Research Article

\title{
Characteristics of Wind Load on Spatial Structures with Typical Shapes due to Aerodynamic Geometrical Parameters and Terrain Type
}

\author{
Yi Zhou $\mathbb{D}^{1},{ }^{1}$ Yuanqi Li $\mathbb{D}^{2},{ }^{2}$ Yingying Zhang $\mathbb{D}^{3},{ }^{3}$ and Akihito Yoshida ${ }^{4}$ \\ ${ }^{1}$ School of Civil Engineering, Southwest Jiaotong University, Chengdu 610031, China \\ ${ }^{2}$ Department of Structural Engineering, Tongji University, Shanghai 200092, China \\ ${ }^{3}$ Jiangsu Key Laboratory of Environmental Impact and Structural Safety in Engineering, China University of Mining and \\ Technology, Xuzhou 221116, China \\ ${ }^{4}$ Wind Engineering Research Center, Tokyo Polytechnic University, Kanagawa 243-0297, Japan \\ Correspondence should be addressed to Yuanqi Li; liyq@tongji.edu.cn
}

Received 26 August 2017; Revised 20 November 2017; Accepted 11 December 2017; Published 29 March 2018

Academic Editor: Pier Paolo Rossi

Copyright (C) 2018 Yi Zhou et al. This is an open access article distributed under the Creative Commons Attribution License, which permits unrestricted use, distribution, and reproduction in any medium, provided the original work is properly cited.

\begin{abstract}
The characteristics of wind load on large-span roofs are complicated by their unique geometrical configurations and strong dependence on aerodynamic geometrical parameters and terrain type. However, there is rarely comprehensive research for characteristics of wind load on spatial structures due to aerodynamic geometrical parameters of roofs and terrain type. In this study, first, the effects of geometrical parameters of roofs and terrain type on the wind pressure distribution based on the data obtained from the existing wind tunnel tests were summarized. Then, the wind loads of full-scale structures were predicted by CFD, and the efficiency of numerical results was further verified by the available wind tunnel tests on spatial structures. Finally, with comparative analyses of the wind pressure distribution of the roofs predicted by CFD under different cases, the effects of shape ratios, especially rise-span ratio, height-span ratio, length-span ratio, and so on, and terrain type on the wind pressure field of typical spatial structures were presented. It can be beneficial to wind-resistant design of structures and can be provided as reference for aerodynamic design optimum of span spatial structures.
\end{abstract}

\section{Introduction}

With the development of science and construction technology, the span spatial structures with good shapes and novel structure have been widely used [1]. This type of structure is very sensitive to the wind load. At present, the wind-resistant design of large-span spatial structures with complicated shapes is mostly on the basis of wind tunnel tests [2]. Nevertheless, wind tunnel has its own limitations. These include but are not limited to the inability to fully model swirling flow impacts on structures (tornadoes) and some types of gust fronts (downbursts); the Reynolds number limitations in accurate modeling wind flows over curved surfaces or flows inside buildings such as natural ventilation or diffusion of pollutants within a partially open enclosure; and the inability to model wind flows in atmospheric boundary layers with various stability conditions [3]. In recent years, the application of CFD to the field of wind engineering has progressed rapidly. At present, numerical solutions have been developed with the potential to overcome the limitations of wind tunnels. The accuracy of CFD predictions is pretty good but not perfect. On the other hand, the use of CFD in wind engineering involves making a number of assumptions and choices regarding such matters as the size of the computational domain surrounding the structure under consideration, the structure of the atmospheric boundary layer at inlet to this domain, the size and distribution of the computational mesh, the order of accuracy of the discretization scheme, and the type of turbulence model to be used to close the time-averaged equations [4]. Such factors translate into fine computational grids and large computer memory and time 
requirements. Thus, further efforts are required in this field in the future.

In this paper, the characteristics of wind load on spatial structures with typical shapes due to aerodynamic geometrical parameters and terrain type have been investigated based on the data obtained from the existing wind experiment and CFD. Firstly, the paper reviewed the current state of the art on wind tunnel tests for several typical kinds of large-span roofs, particularly as it relates to the influence of geometry parameters and terrain type on the characteristics of wind load. Then, this paper simulated typical span spatial structures with atmospheric boundary layer under steady wind field. The flow and dispersion of gases emitted by sources located near different building shapes were determined by the commercial prognostic model FLUENT using the Realizable $k-\varepsilon$ model and the RNG $k-\varepsilon$ model. At last, with comparative analyses of the wind pressure distribution of the roofs predicted by CFD under different cases, the influence of geometrical parameters and terrain type on the wind loads was presented.

The shape and dimension of typical span spatial structures in this paper are shown in Figure 1. The $\theta, \beta, h, f / D, H / D, L / D$, and $b / a$ represent the wind direction angle, roof angle, the horizontal dimension of the sloped steps, rise-span ratio, height-span ratio, length-span ratio, and length-width ratio.

\section{Wind Tunnel Tests of Wind Pressure Distribution on Spatial Structures with Typical Shapes}

2.1. For Roofs with Spherical Surfaces. Spherical roofs are often used for sports buildings, exhibition halls, and so on. When designing these structures, the major concern of structural engineers is often the wind load estimation.

Kawamura et al. [5] carried out a series of experiments to compare the influence of the wind pressure distributed with three kinds of configuration and wind velocity. Blessmann [6] showed several experimental studies of wind effects on domes and the importance of simulation of the main characteristics of natural wind as well as the influence of size and position of openings. Hongo et al. [7] carried out a series of wind tunnel experiments on the mean and fluctuating wind pressures, in which they investigated the effects of the turbulence of approaching flow and the dome's geometry, that is, $f / D$ and $H / D$, on the characteristics of the pressure field. Blessmann [8] carried out wind tunnel experiments on spherical dome with $f / D=0.5$ and 0.25 . Li et al. [9] carried out wind tunnel experiments on spherical dome with $f / D=1 / 3$ and $H=0$. Li et al. [10] discussed the effects of terrain type and wind direction on the wind pressure of roofs and analyzed the negative peak local shape factors under each wind direction with their positions.

According to these experimental results, it may be concluded as follows:

(1) The effect of $f / D$ is more significant than that of $H / D$. The wind suction at the top of roof and the positive pressure of windward increase with $f / D$ increasing.

(2) When $f / D$ is between 0.2 and 0.3 , the pressure of roof is positive at the windward and at the wake. However, the value cannot be confirmed due to limited wind tunnel test data.

(3) When power law exponent $\alpha>0.23$, the effect of terrain type on the pressure field of the spherical dome is insignificant.

2.2. For Roofs with Cylindrical Surfaces. Cylindrical roofs are increasingly used in the modern built environment because they offer aerodynamically efficient shapes. However, they are sensitive to wind. The current aerodynamic coefficients do not contemplate the possibility of existence of canopies attached to the buildings.

Paluch et al. [11] discussed the relation between the magnitude of the canopy design forces and the canopy width, as well as the relation between the canopy height location and the height of the building wall. Blackmore and Tsokri [12] described a series of parametric wind tunnel studies undertaken at BRE to measure wind pressures on a wide range of curved roof models in a properly scaled atmospheric boundary layer simulation. Li et al. [13] researched the wind pressure distribution of cylindrical roofs with $f / D=1 / 3$ and $L / D=1.0-3.0$. Chen and Yang [14] investigated the effects of rise-span ratio and roof inclination on the characteristics of wind pressure.

According to these experimental results, it can be concluded as follows:

(1) The influence of $H / D$ on the wind pressure distribution is limited besides the windward side. Paluch et al. [11] showed that the wind pressure of the windward side near roofing edge under certain geometrical parameter is negative, while Blackmore and Tsokri [12] showed that the wind pressure of all windward side under any geometrical parameters is positive. It may be because the flow separated from the roofing edge is serious.

(2) The influence of $f / D$ and $L / D$ on the wind pressure distribution is significant. The suction at the windward side decreases, while wind suction at the top of the roof increases with $f / D$ increasing. When $L / D<3$, the peak value of suction at the top of the roof increases with $L / D$ increasing; when $L / D>3$, the flow is changing in nature from three-dimensional flow on the end sections to two-dimensional flow in the central section, and the wind pressure distribution and the peak value change insignificantly with $L / D$ increasing.

2.3. For Roofs with Saddle-Shaped Surfaces. In addition to the roofs with spherical surfaces and cylindrical surfaces, the saddle-shaped roofs with negative Gaussian curvature have also been used widely. Some scholars carried out wind tunnel tests on this type of roof. The $\theta=0^{\circ}$ is defined as the wind blow out along two higher points, and the $\theta=90^{\circ}$ is defined as the wind blow out along two lower points.

Dutt [15] presented wind tune tests on the wind pressure distribution of saddle-shaped roofs with $f / D=1 / 10$ and $\theta=0^{\circ}$. Zhao et al. [16] carried out wind tunnel tests on saddle-shaped roofs with $f / D=1 / 10,1 / 12,1 / 16$, and $1 / 20$ and 


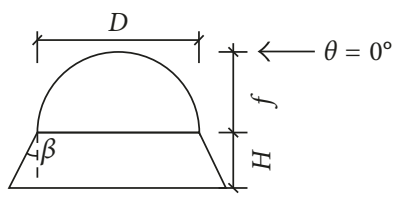

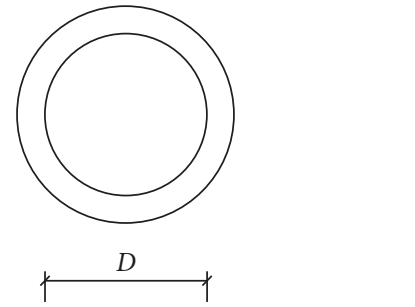

(a)
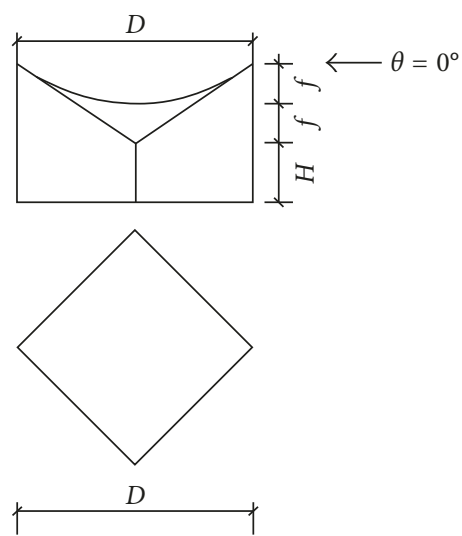

(c)

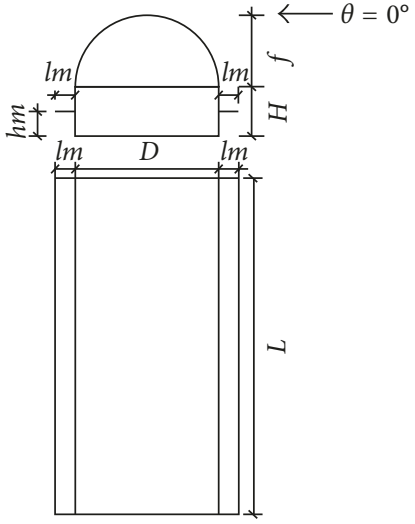

(b)
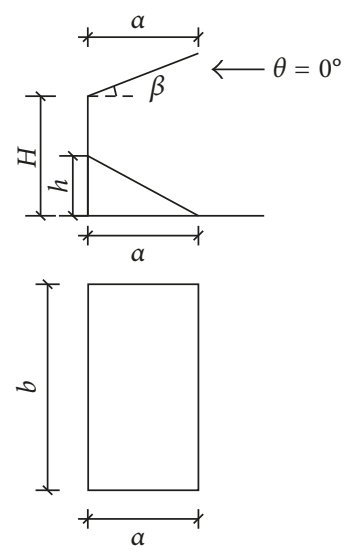

(d)

Figure 1: Shape and dimension of typical spatial structures. (a) Spherical surfaces, (b) cylindrical surfaces, (c) saddle-shaped surfaces, and (d) cantilevered roofs.

$H / D=1 / 5$ and studied the influence of $f / D$ and wind direction on the wind pressure distribution. Sun [17] reported wind tunnel data for the saddle-shaped roofs with $f / D=1 / 12$ and $1 / 8$ and $H / D=1 / 8,1 / 6$, and $1 / 4$, under the uniform flow field and suburban terrain. Dong and Ye [18] investigated the point pressure and area-averaged wind pressure distributions of the saddle-shaped roofs with $f / D=1 / 6$ and $1 / 12$, respectively, occurring below conical vortices through wind tunnel experiments. Liu et al. [19] investigated the characteristics of dynamic pressures of a saddle-shaped roof under various wind directions and approaching wind conditions based on wind tunnel experiment data. Li et al. [20] presented a study on the characteristics of dynamic wind pressures on the saddle-shaped net roof under the open and urban terrains in a wind tunnel. The power law exponents under the open and urban terrains are 0.16 and 0.30 , respectively.

According to these experimental results, it can be concluded as follows:

(1) The effect of $f / D$ on the wind pressure distribution is significant. The wind pressure at the windward side decreases and the roof pressure pattern changes insignificantly with $f / D$ increasing.
(2) The difference of the wind pressure coefficient between the uniform flow field and the suburban terrain is not dramatic.

2.4. For Cantilevered Roofs. Grandstand roofs are mostly large roof structures cantilevered at the rear of grandstands. Characteristics of wind pressures on large horizontal cantilevered roofs were investigated recently by the present authors. Simultaneous pressure measurements were made on both surfaces of a wind tunnel roof model.

Zhao and Lam [21] showed wind tunnel tests performed on a rigid model of a horizontal grandstand roof. The prototype dimensions of the roof were $78 \mathrm{~m} \times 15 \mathrm{~m}$ at a height of $18 \mathrm{~m}$. Zhao and Lam [22] carried a series of experiments to research the influence of slope on the wind pressure distribute of the cantilever roofs. The investigation covers a downsloping roof configuration at the roof angle $-5^{\circ}$ and two upsloping roof configurations at the roof angles $5^{\circ}$ and $10^{\circ}$. Katsumura et al. [23] showed wind tunnel data for a cantilever roof. The wind pressure model of the roof used in the experiments had a width of $0.24 \mathrm{~m}$, a span of $0.18 \mathrm{~m}$, and a height of $0.18 \mathrm{~m}$. The roof had a slope of $5^{\circ}$.

According to the existing wind tunnel test, it can be concluded as follows: 
(1) The cantilevered roof surface is mainly under suction.

(2) The roof pressure pattern is found to change significantly with the roof angles. The whole suction increases when $\beta$ increases from $-5^{\circ}$ to $10^{\circ}$, and when $\beta>5^{\circ}$, the whole suction changes insignificantly.

\section{Suitability of CFD Investigations on Wind Pressure Distribution on Spatial Structures with Typical Shapes}

Significant progress in the field of CFD has been made, and it has been used as an efficient tool for the prediction of wind loads. Using a large eddy simulation (LES) and a low Reynolds number (Re) type model can obtain more accurate results. However, it is difficult to use those models for practical analysis because many computational cases and a huge number of grids are required for the prediction and analysis of the pedestrian wind environment under severe time restrictions [24]. Hence, the numerical simulation is mainly based on high Re number Reynolds-averaged Navier-Stokes (RANS) equation models. Because RANS equation modeling can reasonably simulate mean wind characteristics and requires less computing time than other CFD methods, it is the most widely used method in many industrial applications. For the numerical simulation, the governing equations of the incompressible turbulent wind flow around buildings are presented by the RANS equations as follows:

$$
\begin{aligned}
\frac{\partial}{\partial x_{i}}\left(\rho u_{i}\right)= & 0 \\
\frac{\partial}{\partial t}\left(\rho u_{i}\right)+\frac{\partial}{\partial x_{j}}\left(\rho u_{i} u_{j}\right)= & -\frac{\partial p}{\partial x_{i}}+\mu \frac{\partial}{\partial x_{j}}\left(\frac{\partial u_{i}}{\partial x_{j}}\right) \\
& +\frac{\partial}{\partial x_{j}}\left(-\rho \overline{u_{i}^{\prime} u_{j}^{\prime}}\right) .
\end{aligned}
$$

The turbulent kinetic energy, the $k$ equation in Realizable $k-\varepsilon$ model, is the same as that in the standard $k-\varepsilon$ model and the RNG $k-\varepsilon$ model. However, the form of the $\varepsilon$ equation in Realizable $k-\varepsilon$ model is quite different from that in the standard $k-\varepsilon$ model and RNG $k-\varepsilon$ model. One of the noteworthy features is that the production term in the $\varepsilon$ equation does not involve the production of $k$. It is believed that the present form better represents the spectral energy transfer. The RNG $k$ - $\varepsilon$ turbulence model is derived from the instantaneous Navier-Stokes equations, using a mathematical technique called "renormalization group" methods. It is a mathematical theory which can be used to derive a turbulence model which is similar to the $k-\varepsilon$ model. Compared to standard $k-\varepsilon$ model, RNG $k-\varepsilon$ model has the following advantages: (1) the additional term in the $\varepsilon$ equation improves the accuracy when modeling rapidly strained flows, (2) the effect of swirl turbulence is included in the RNG model, (3) the RNG model enables to use Prandtl numbers (turbulent viscosity/turbulent heat conductivity) as variables, and (4) RNG model enables to use lower Reynolds numbers than in standard model. The analytical derivation results in a model with constants different from those in the standard $k$ - $\varepsilon$ model and additional terms and functions in the transport equations for $k$ and $\varepsilon$. According to the above characteristics, the Realizable $k-\varepsilon$ model and RNG $k-\varepsilon$ model are probably the more effective and efficient solution for future development.

Richards et al. [25] compared the standard $k-\varepsilon$, the MMK $k-\varepsilon$, and the RNG $k-\varepsilon$ turbulence models. They found that the error of the standard model calculation results and the fullscale model measurement data is large, especially in the flow separation region. In fact, the standard $k-\varepsilon$ model of turbulence does not allow for anisotropic diffusivities in threedimensional strain fields, its representation of the effects of streamline curvature (which are expected to be quite pronounced around the windward eaves) is quite inadequate, and its response to the application and removal of streamwise pressure gradients is poor. The rate of production of $k$ seems always to be exaggerated, leading to higher than expected levels of turbulence kinetic energy (and thus higher eddy viscosity). Thus, when used for pitched-roofed buildings, the standard $k-\varepsilon$ model either underestimates the extent of the region of the large-scale separation that occurs over the windward roof or fails to predict its occurrence altogether. Hence, this paper selects the RNG $k-\varepsilon$ model and Realizable $k-\varepsilon$ model to simulate the wind field.

In the Fluent, it is necessary to impose the boundary condition artificially because the computational domain cannot be infinite. Velocity inlet boundary conditions are used to define the flow velocity. The outflow boundary condition is obeyed in fully developed flows where the diffusion flux for all flow variables in the exit direction is zero. Basin at the top and on both sides of the use of symmetric boundary conditions is equivalent to the free-slip wall. The no-slip boundary condition is enforced at the wall of the model surface and the ground. Adopting of the nonbalanced wall surface function simulates the complex phenomenon of flow nearby the wall of the surface, which is characterized by impingement, separation, reattachment, circulation, vortices, and so on. Using user-defined functions (UDFs) which Fluent provides to program can realize the wind profile of atmospheric boundary layer, turbulent kinetic energy $k$, and turbulence dissipation rate $\varepsilon$.

\subsection{For Roofs with Spherical Surfaces}

3.1.1. Spherical Roof Model in the Numerical Wind Tunnel. In the numerical wind tunnel, the spherical roof model for calculating is selected with a radius of $60 \mathrm{~m}$ and height of $40 \mathrm{~m}$, computational domain is taken as $1800 \mathrm{~m} \times 1000 \mathrm{~m} \times 350 \mathrm{~m}$, and the building is located at the air flow of 1/3. Li et al. [9] simulated section terrains II, III, and IV of wind profile according to the definition of the Architectural Institute of Japan [26]. The wind velocity vertical distribution coefficient was set equal to $E_{r}=U(z) / U_{10}^{\amalg}$. $U_{10}^{\amalg}$ was wind velocity at $10 \mathrm{~m}$ height from the ground in terrain II. The inlet profiles for $k$ and $\varepsilon$ were specified by $k=0.5(U(z) \cdot I)^{2}$ and $\varepsilon=0.09^{3 / 4} k^{3 / 2} / 50$. In wind tunnel test, the reference wind velocity at the top of the models was near 


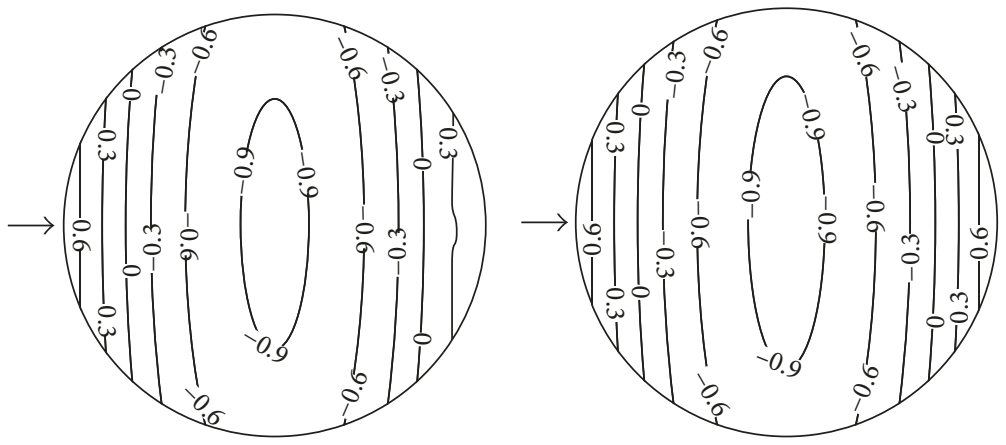

(a)

(b)

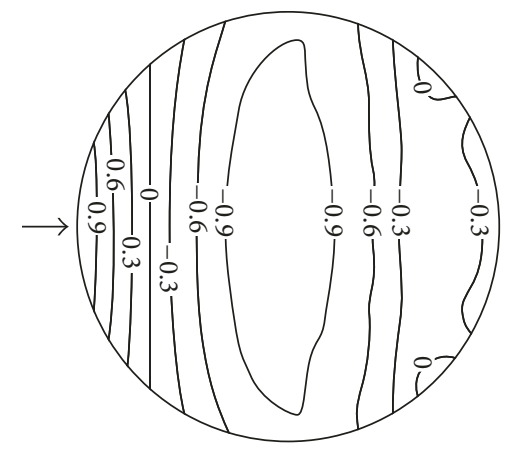

(c)

Figure 2: Mean pressure coefficient distributions of the spherical model predicted with two turbulence models. (a) RNG $k-\varepsilon$ model, (b) Realizable $k-\varepsilon$ model, and (c) wind tunnel result [9].

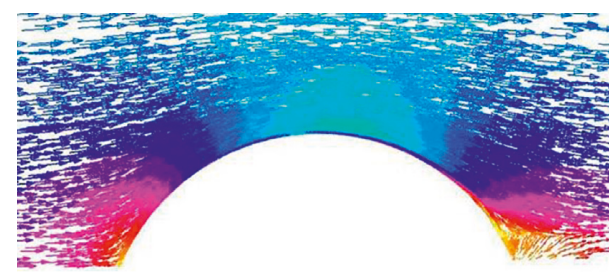

FIGURE 3: Wind vector around spherical roof.

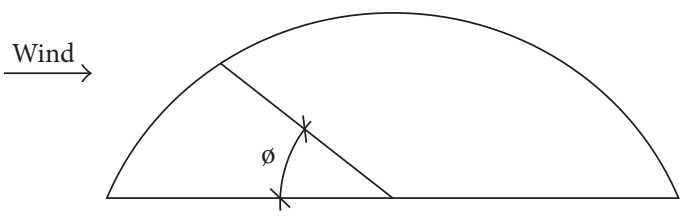

Figure 4: Centerline of the roofs along the wind direction angle.

to $6 \mathrm{~m} / \mathrm{s}$ and the wind velocity ratio was $1: 4$. Hence, the wind velocity corresponding to the numerical simulation of CFD at the entrance is $24 \mathrm{~m} / \mathrm{s}$.

3.1.2. The Results of Spherical Roof. The results of adopting the RNG $k-\varepsilon$ model and Realizable $k-\varepsilon$ model to simulate the wind field on the spherical shell under different terrain types based on AIJ are given in Figure 2. The power law exponent $\alpha$ under terrain II is 0.15 . As shown in Figure 2, the mean pressure coefficient distributions derived by two turbulence models are consistent with the wind tunnel results. The majority of spherical roof is under negative pressure with the

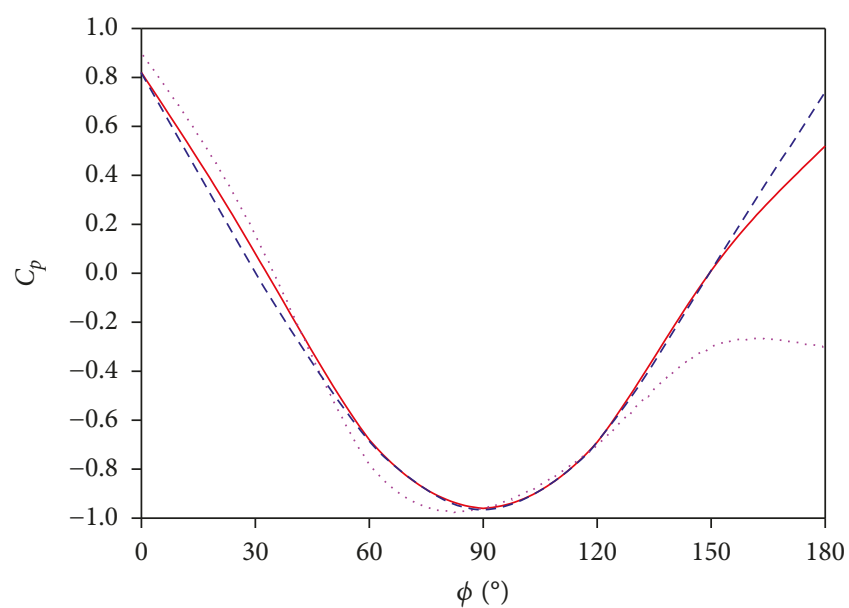

RNG $\kappa-\varepsilon$ model

- - - Realizable $\kappa-\varepsilon$ model Wind tunnel test

Figure 5: Comparison of the results between numerical wind tunnel and wind tunnel tests [9] under terrain II.

exception of a small portion of the windward side under positive pressure. The absolute value of the mean wind force coefficient at the top is much greater than that at the other area. Comparing to the Realizable model, the wind pressures distribution and values derived by the RNG model are relatively closer to the wind tunnel result. However, the realizable model is relatively easy to provide 


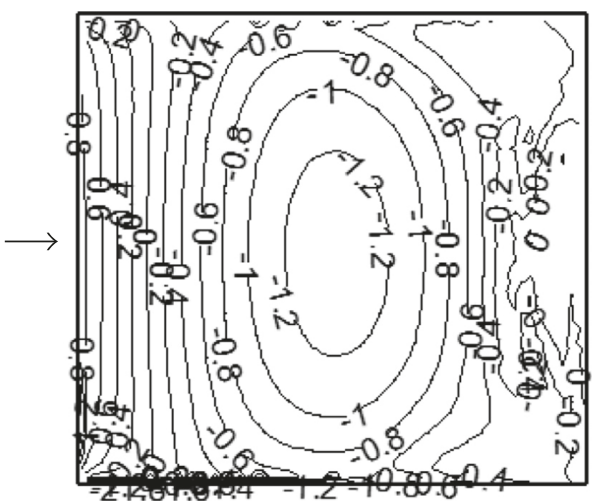

(a)

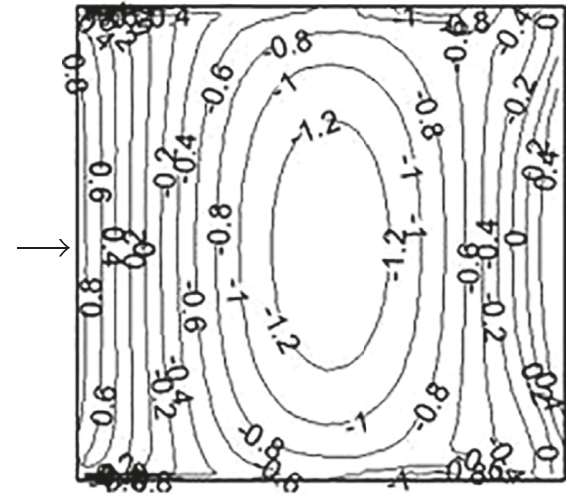

(b)

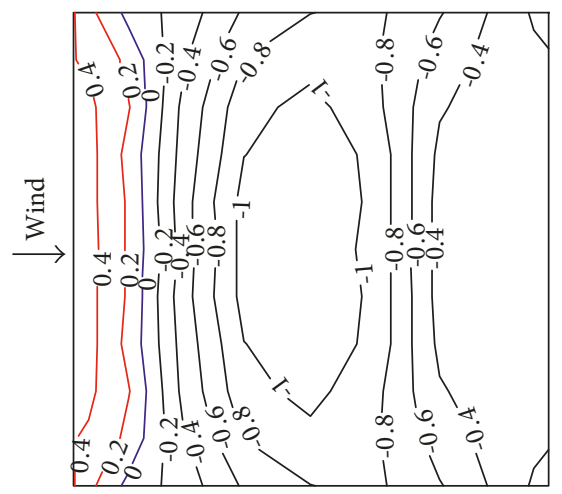

(c)

FIGURE 6: Mean pressure coefficient distributions of the cylindrical model predicted with two turbulence models. (a) RNG $k$ - $\varepsilon$ model, (b) Realizable $k-\varepsilon$ model, and (c) wind tunnel result [13].

good convergence performance. Figure 3 gives the wind vector around the spherical model according to the RNG model. It can be seen that there is a small positive region at the wake due to the flow reattachment downstream. However, wind tunnel tests do not show this phenomenon.

As shown in Figure 4, it defines that the centerline of the roofs would be along the wind direction angle. Figure 5 gives the comparison of the mean pressure coefficients along the centerline between numerical wind tunnel and wind tunnel tests. As shown in Figure 5, it indicates that the results predicted by the two turbulence models at the windward and at the central zone are in agreement with the wind tunnel test. Because of large-span roofs with some high Reynolds numbers $\left(10^{6}<\operatorname{Re}<10^{8}\right)$, adopting the numerical simulation of CFD may be difficult to obtain perfect results compared with wind tunnel tests with different Reynolds number, especially for leeward part of curve surfaces.

\subsection{For Roofs with Cylindrical Surfaces}

3.2.1. Cylindrical Roof Model in the Numerical Wind Tunnel. In the numerical wind tunnel, the dimensions of the roof are $130 \mathrm{~m} \times 130 \mathrm{~m}$ at a height of $43 \mathrm{~m}$, computational domain is taken as $1800 \mathrm{~m} \times 1000 \mathrm{~m} \times 350 \mathrm{~m}$, and the building is located at the flow of $1 / 3$. Li et al. [13] simulated section terrains II, III, and IV of wind profile according to AIJ. In the wind tunnel test, the reference wind velocity at

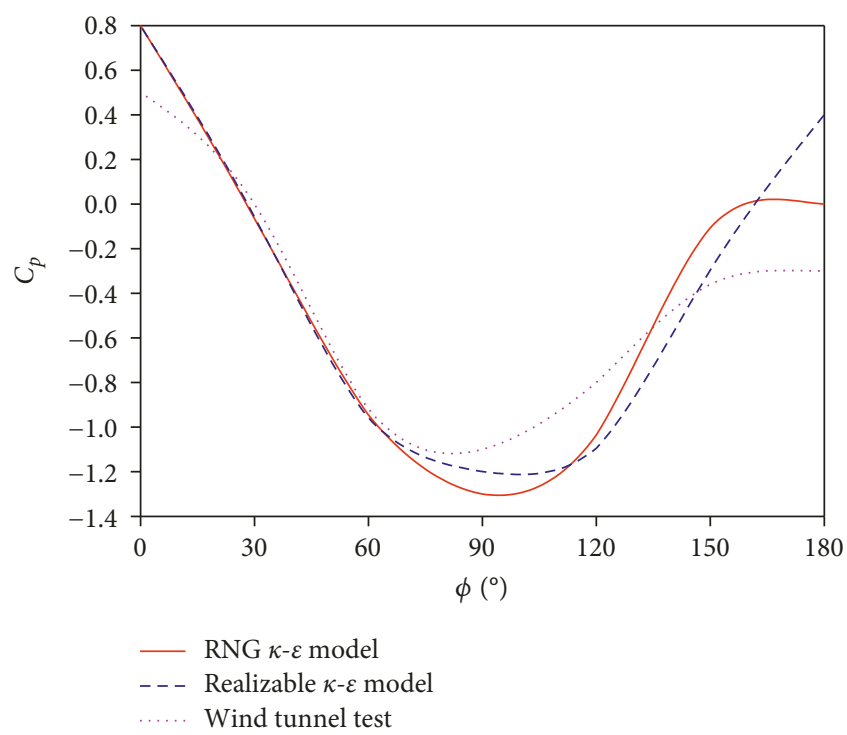

FIgURE 7: Comparison of the results between numerical wind tunnel and wind tunnel tests [13] under terrain II with $L / D=1.0$.

the top of the models was near to $6 \mathrm{~m} / \mathrm{s}$ and the wind velocity ratio was $1: 4$. Hence, the wind velocity corresponding to the numerical simulation of CFD at the entrance is $24 \mathrm{~m} / \mathrm{s}$. 


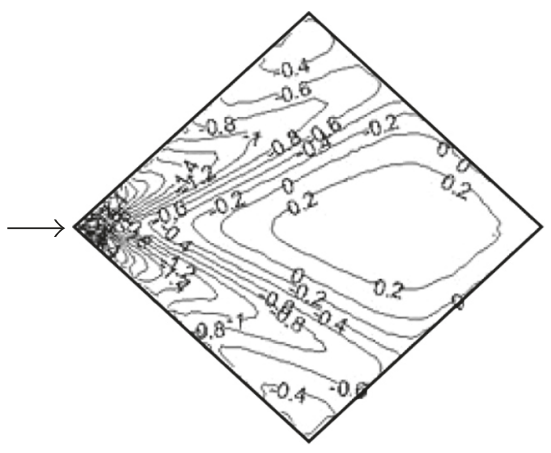

(a)

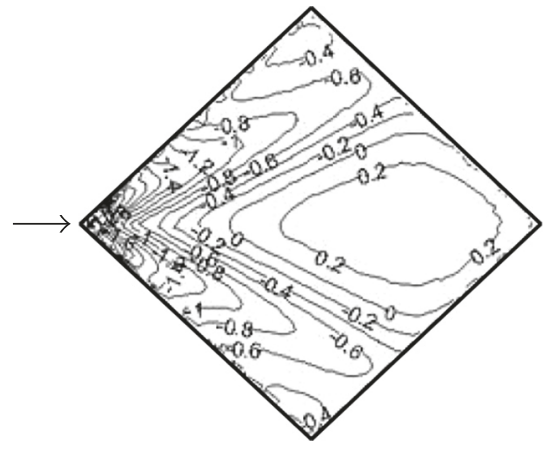

(b)

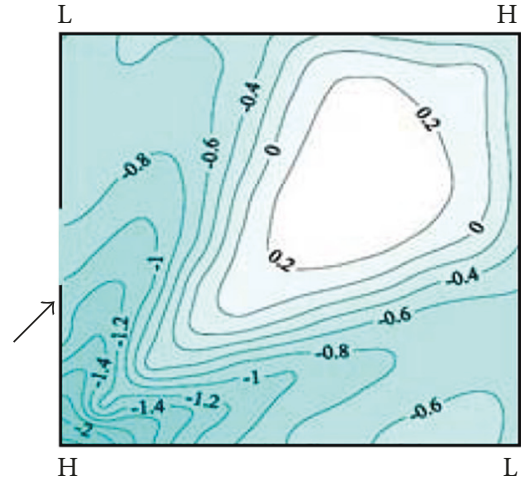

(c)

FiguRE 8: Mean pressure coefficient distributions of the saddle-shaped model predicted with two turbulence models. (a) RNG $k-\varepsilon$ model, (b) Realizable $k-\varepsilon$ model, and (c) wind tunnel test [17].

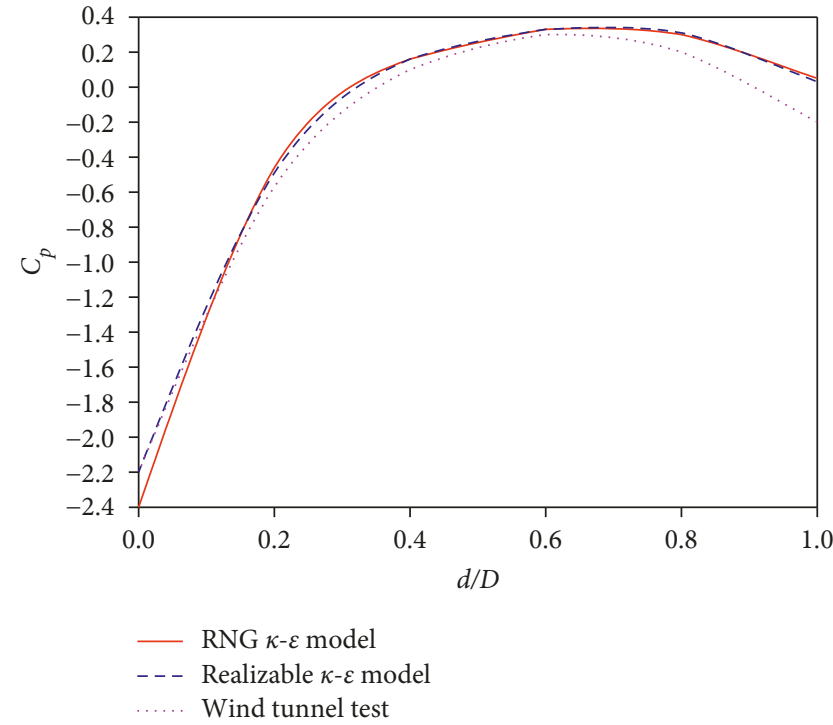

(a)

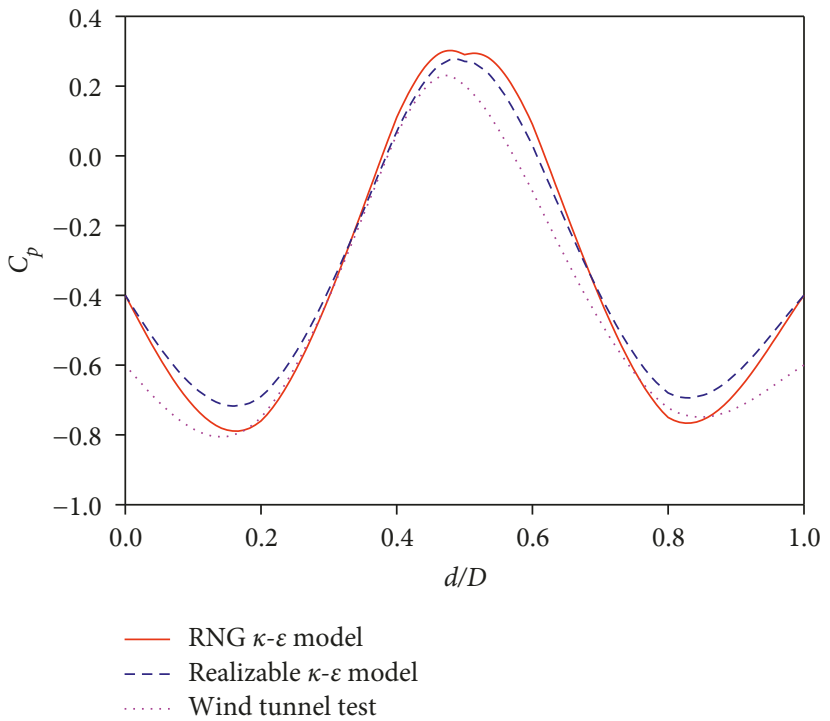

(b)

FIGURE 9: Comparison of the results between numerical wind tunnel and wind tunnel tests [17] under terrain B. (a) Two higher points of line and (b) two lower points of line.

3.2.2. The Results of Cylindrical Roof. The results of adopting the RNG $k-\varepsilon$ model and Realizable $k-\varepsilon$ model to simulate the wind pressure field of the cylindrical shell with $L / D=1.0$ under terrain II based on AIJ are given in Figure 6. The power law exponent $\alpha$ is 0.15 . As shown in Figure 6, the mean wind pressure coefficient distributions derived by two turbulence models are basically consistent with the wind tunnel test results. The flow fiercely dashes the roof at the windward and the region pressure shows positive. The positive pressure transforms into negative near the center zone of the roof and arrives the maximum values at the top. Comparing the Realizable model, the mean wind pressure coefficients given by the RNG model at the wake are disorder; however, the results of RNG model are relatively closer to wind tunnel test results.
The comparison of the mean pressure coefficients between numerical simulation and wind tunnel test results under terrain II is given in Figure 7. As shown in Figure 7, it indicates that the results predicted by the two turbulence models at the windward and at the central zone are in agreement with the wind tunnel test. However, at the wake, optimization of the Realizable model shows that there is still a small positive pressure zone at the wake, optimization of Realizable model shows that the pressure tends to zero at the same zone, and the wind tunnel test result shows the negative pressure.

\subsection{For Roofs with Saddle-Shaped Surfaces}

3.3.1. Saddle-Shaped Roof Model in the Numerical Wind Tunnel. In the numerical wind tunnel, the roof with the saddle-shaped surface is constructed with $80 \sqrt{2} \mathrm{~m} \times 80 \sqrt{2} \mathrm{~m}$ 
TABLE 1: Mean pressure coefficient distribution of the cantilevered roofs predicted with two turbulence models.

Wind tunnel tests [22]

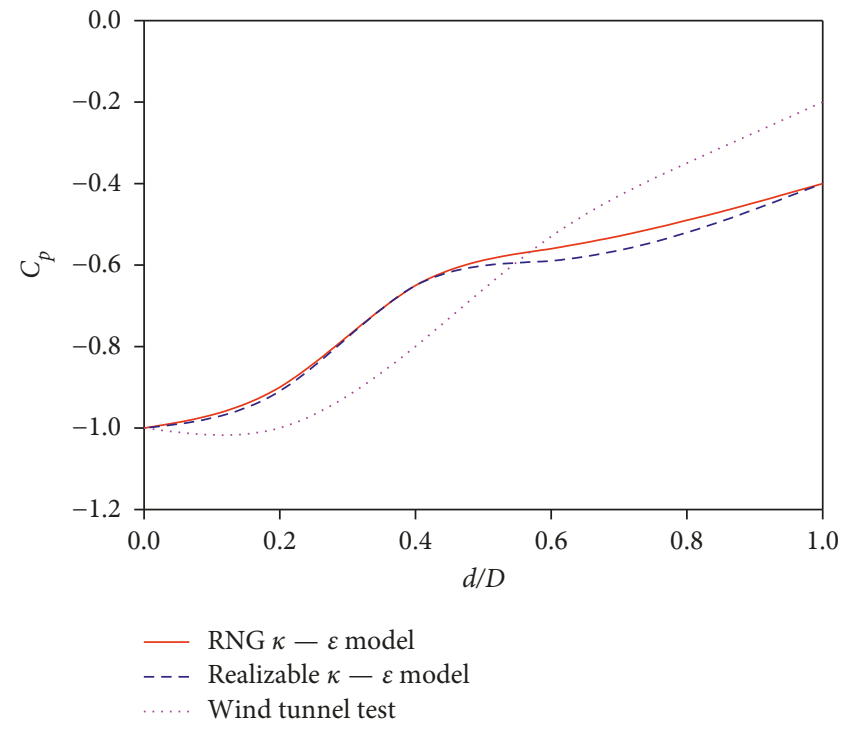

(a)

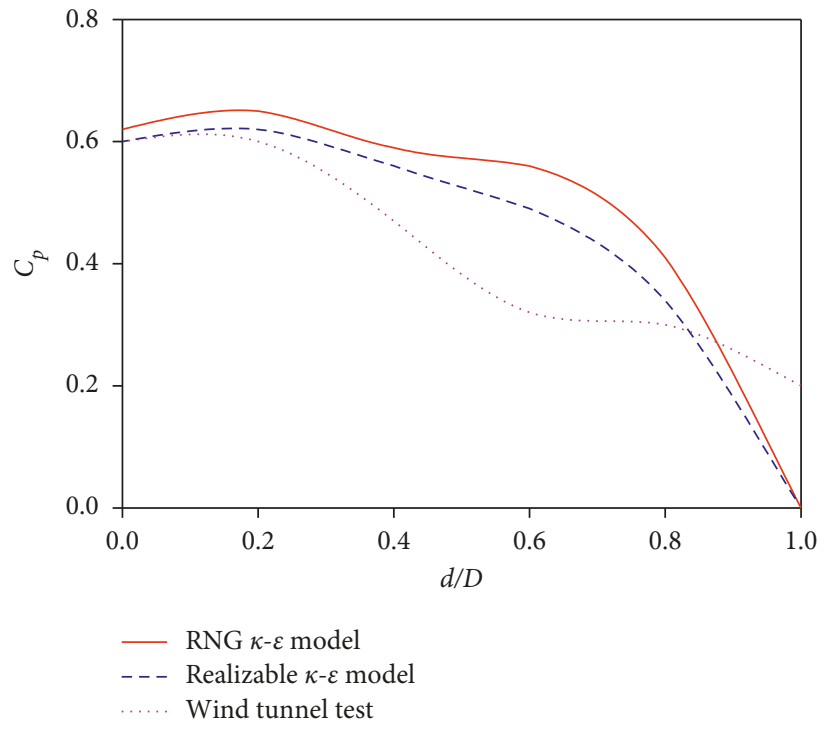

(b)

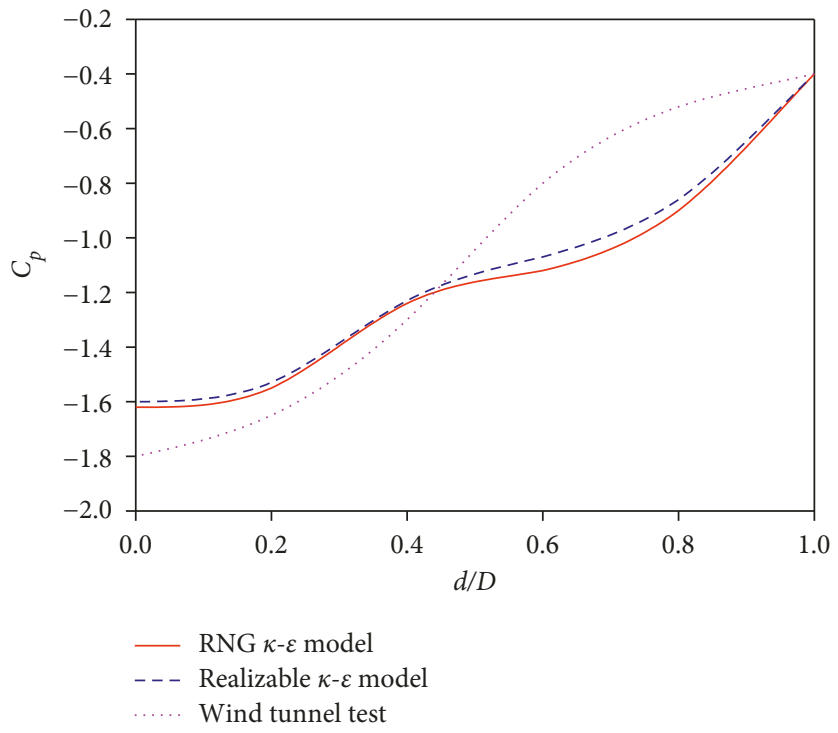

(c)

FiguRE 10: Comparison of the results between numerical wind tunnel and wind tunnel tests [22] under $\alpha=0.19$. (a) Upper roof, (b) lower roof, and (c) net value. 


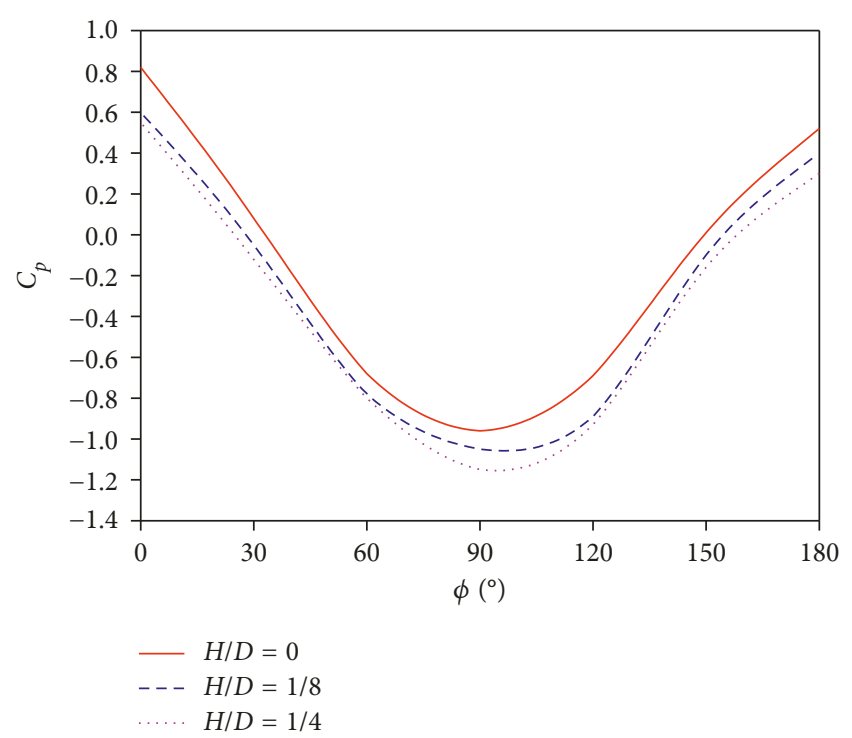

FIGURE 11: Mean pressure coefficient distributions with different $H / D(f / D=1 / 3)$.

at an eaves height of $20 \mathrm{~m}, f / D$ of $1 / 8$, and $H / D$ of $1 / 8$, computational domain is taken $1800 \mathrm{~m} \times 1000 \mathrm{~m} \times 350 \mathrm{~m}$, the building is located at the flow of $1 / 3$.

Sun [17] simulated wind profile under the suburban terrain according to Load Code for the Design of Building Structures of China (GB50009-2012) [27] and turbulence intensity profiles according to Australian and New Zealand code [28]. In the wind tunnel test, the average canopy height model is chosen as a reference point of the mean pressure coefficient. The wind velocity was $9 \mathrm{~m} / \mathrm{s}$ and the wind velocity ratio was $1: 2$. Hence, the wind velocity corresponding to the numerical simulation of CFD at the entrance is $18 \mathrm{~m} / \mathrm{s}$.

3.3.2. The Results of Saddle-Shaped Roof. The results of adopting the RNG model and the Realizable model to predict the wind pressure field of saddle-shaped roof with $f / D=1 / 8$ and $H / D=1 / 8$ under the suburban terrain according to GB50009-2012 are given in Figure 8. The power law exponent $\alpha$ is 0.16 . As shown in Figure 8 , the mean pressure coefficient distributions derived two turbulence models that are basically consistent with wind tunnel test results. The saddle-shaped roof is still primarily under the suction. The wind pressure on the corner or the edge of the windward side is much greater than that on other areas. The results given by the RNG model and the Realizable model are close to wind tunnel test results.

The comparison of the mean pressure coefficients between numerical wind tunnel and wind tunnel tests under terrain $B$ is shown in Figure 9, when $\theta=0^{\circ}$. It shows that along the direction of two higher points of line, when $d / D=0-0.3$, the roof is under negative pressure, when $d / D=0.3-0.9$, the roof is under positive pressure, and when $d / D=0.9-1.0$, the roof is under small negative pressure. It shows that along the direction of two lower points of line, when $d / D=0-0.4$ and $0.6-1$, the roof is under negative pressure, when $d / D=0.4-0.6$, the roof is under positive pressure.

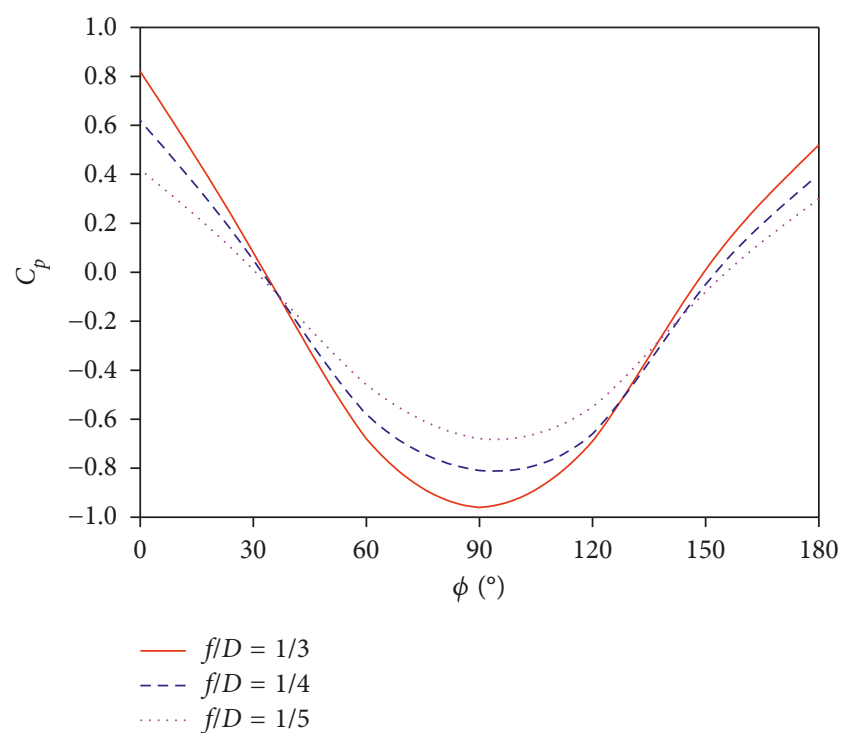

FIGURE 12: Mean pressure coefficient distributions with different $f / D(H / D=0)$.

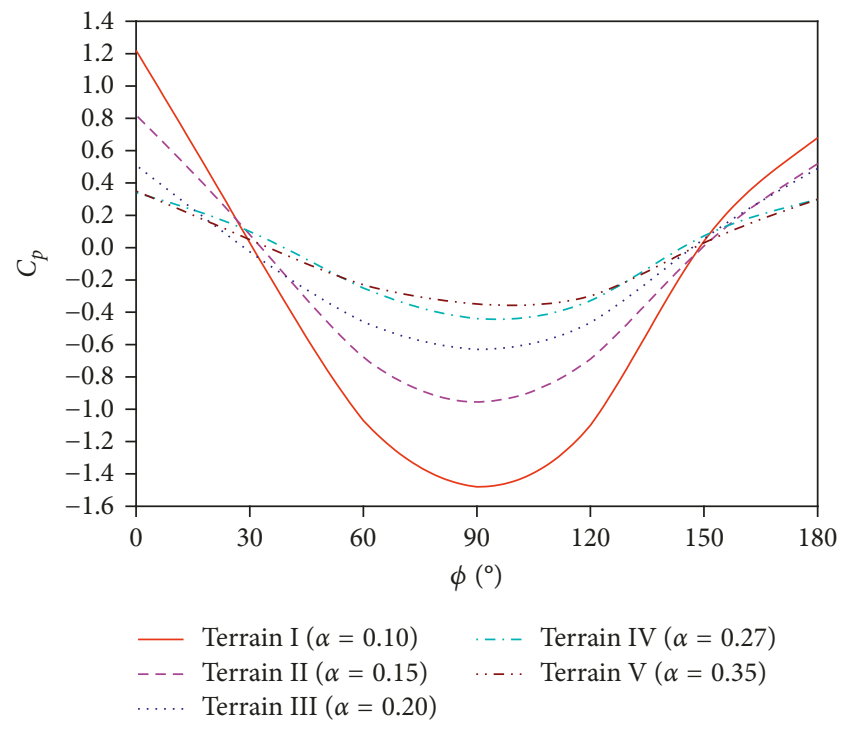

FIgURE 13: Mean pressure coefficient distributions along the centerline under different terrain types.

\subsection{Numerical Simulation on Wind Pressure on Cantilevered Roofs}

3.4.1. Cantilevered Roof Model in the Numerical Wind Tunnel. In the numerical wind tunnel, the dimensions of the roof are $78 \mathrm{~m} \times 15 \mathrm{~m}$ at a height of $18 \mathrm{~m}$. The roof inclination is $0^{\circ}$. Underneath the roof was a model of a stepped grandstand $135 \mathrm{~mm}$ high. Computational domain is taken as $1500 \mathrm{~m} \times 1000 \mathrm{~m} \times 350 \mathrm{~m}$, and the building is located at the flow of $1 / 3$.

Zhao and Lam [22] simulated general type terrain in the Hong Kong Wind Code, which specified $\alpha$ of 0.19 for the mean wind velocity profile. The turbulence intensity was specified by $I_{h}=0.1055 \times(h / 90)^{-0.11}$. During the tests, the 


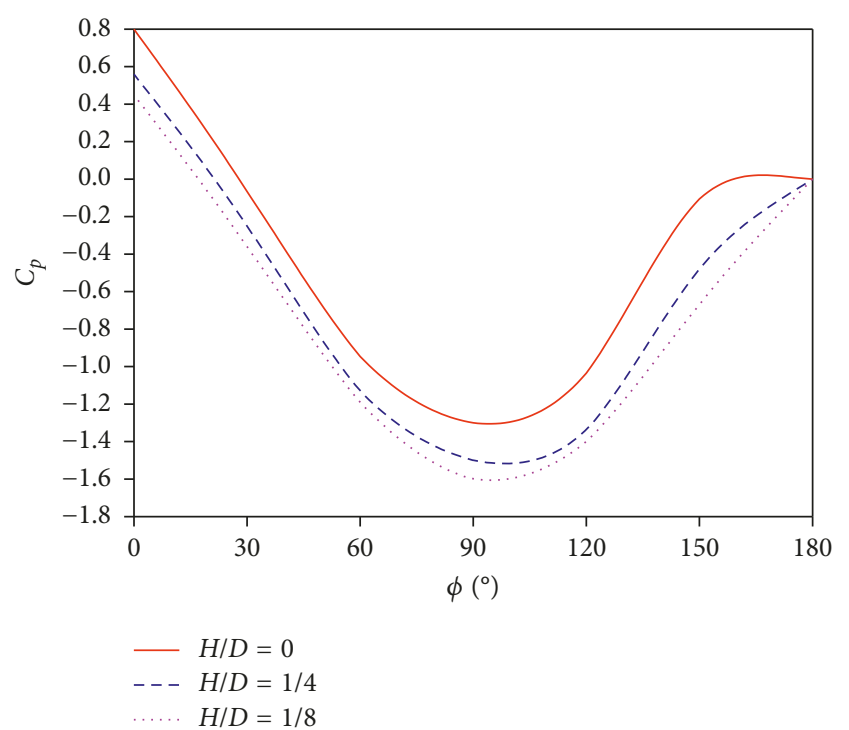

FIgURE 14: Mean pressure coefficient distributions with different $H / D(f / D=1 / 3 ; L / D=1)$.

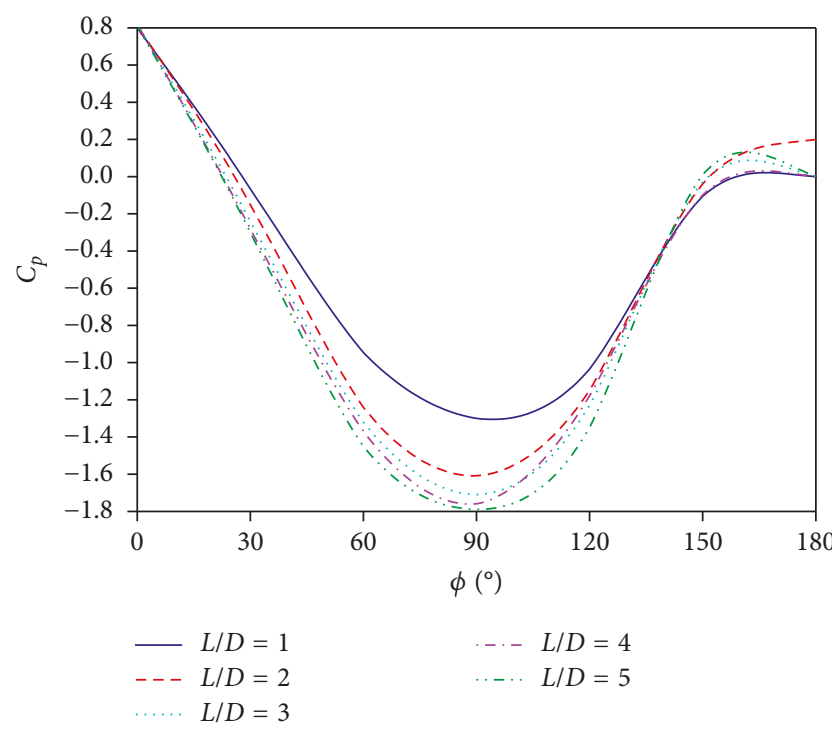

FIgURE 15: Mean pressure coefficient distributions with different $L / D(H / D=0 ; f / D=1 / 3)$.

wind tunnel was run with a wind velocity of about $10 \mathrm{~m} / \mathrm{s}$ at the roof height and this velocity corresponded to the extreme wind conditions in Hong Kong at a velocity ratio of $1: 4$. Hence, the wind velocity corresponding to the numerical simulation of CFD at the entrance is $40 \mathrm{~m} / \mathrm{s}$.

3.4.2. The Results of Cantilevered Roof. The results of using the RNG model and the Realizable model to simulate the wind field of cantilevered roofs under the same terrain type with the wind tunnel test are shown in Table 1. Due to the symmetry, the roof is taken half in Table 1. Two turbulence models can reflect the mean pressure coefficients distribution, which basically are consistent with the results of the wind tunnel test. However, the Realizable model is relatively easy to

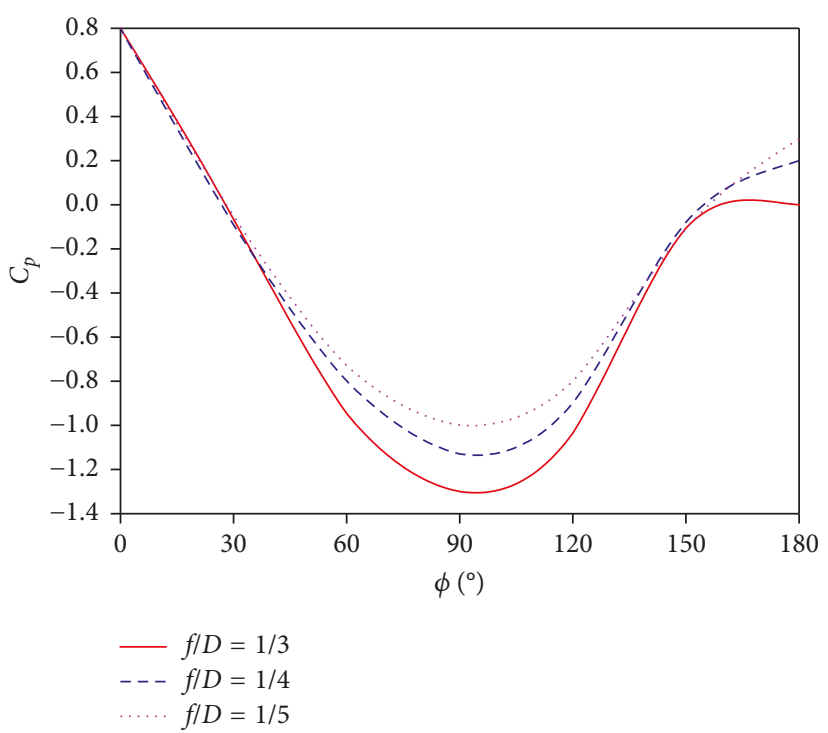

FIGURE 16: Mean pressure coefficient distributions with different $f / D(H / D=0 ; L / D=1)$.

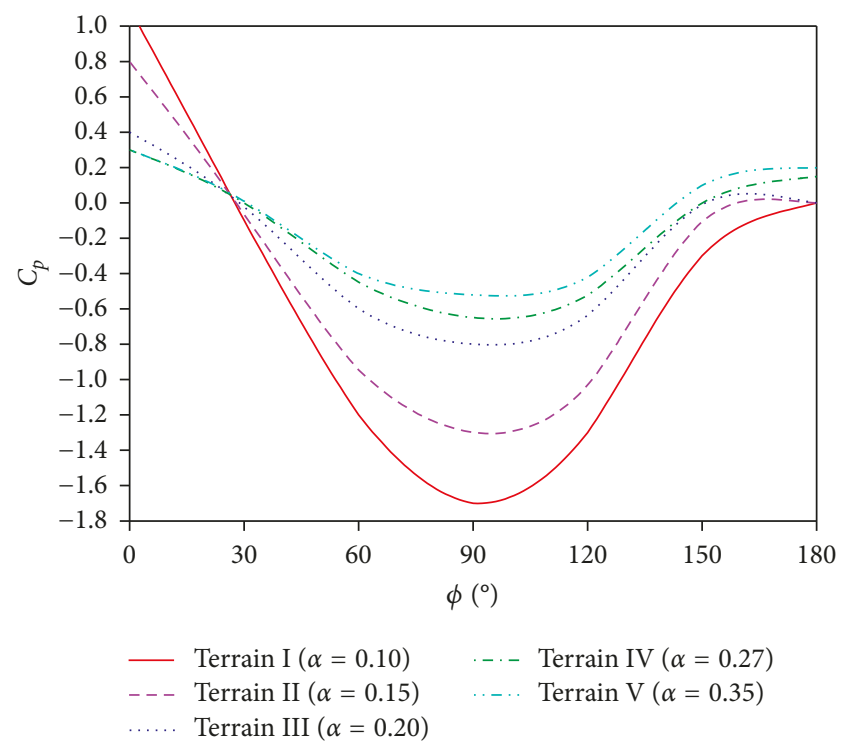

FIGURE 17: The mean pressure coefficient distributions along the centerline under different terrain types with $L / D=1.0$.

provide good convergence performance and offers orderly pattern of pressure contour lines. For a horizontal roof, flow separates at the leading edge and may reattach downstream. The entire upper roof is under suction, and the entire lower roof is under positive pressure. Highest net wind pressure is found at the frontal part of the roof and the pressure level decreases in going downwind to the rear edge of the roof. The net wind pressure is contributed more significantly by the upper roof pressure than by the lower roof pressure, both in magnitude and in distribution patterns.

The comparison of the mean pressure coefficients along the centerline of the cantilevered roof between numerical wind tunnel and wind tunnel tests under wind attack angle of $0^{\circ}$ is shown in Figure 10. In this figure, $d$ means the distance 


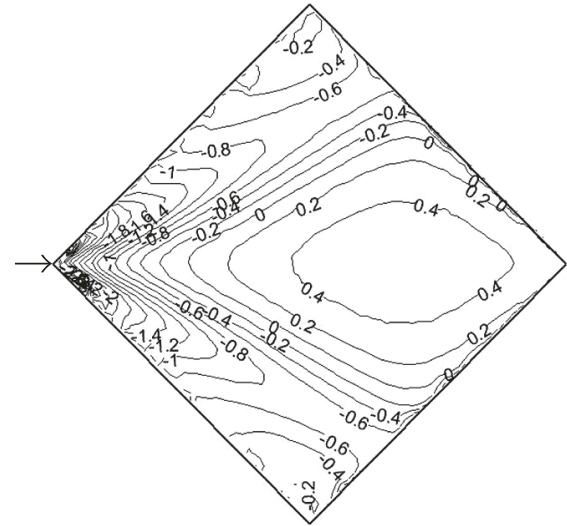

(a)

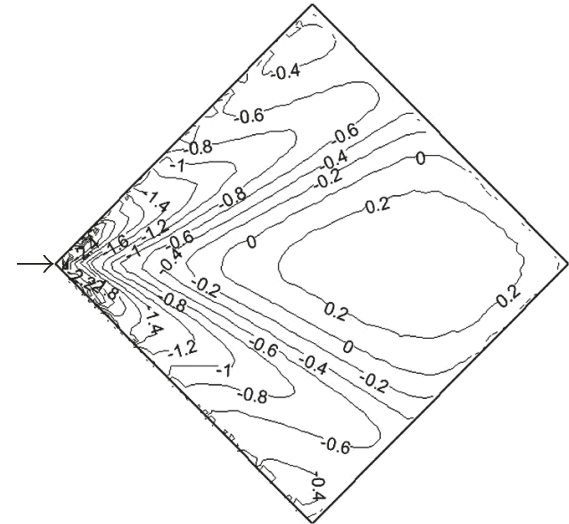

(b)

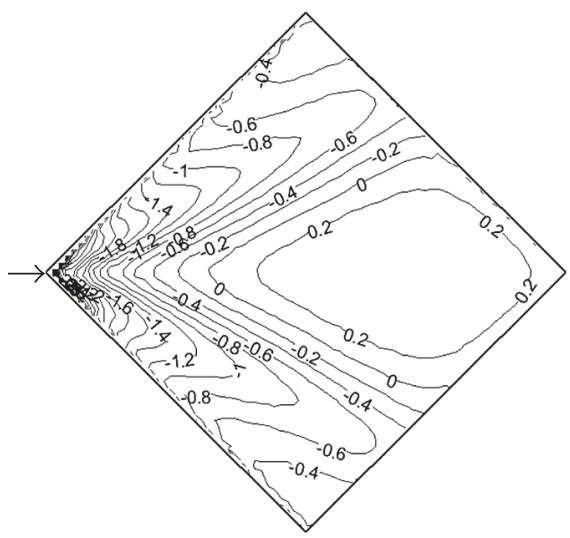

(c)

Figure 18: Mean pressure coefficient distributions of the saddle-shaped model $(f / D=1 / 3)$. (a) $H / D=0$, (b) $H / D=1 / 8$, and (c) $H / D=1 / 4$.

from the leading edge and $b$ means the cantilevered roof depth. For the net pressure, at the leading edge, the absolute values derived by the numerical wind tunnel are smaller than wind tunnel test results; however, at the wake, the absolute values derived by the numerical wind tunnel are bigger than the wind tunnel tests. The error between numerical wind tunnel and wind tunnel tests is about $25 \%$. Compared with cantilevered roofs, the results of spherical, cylindrical, and saddle-shaped roofs using the RNG model and the Realizable model are close to wind tunnel results. It may be that as the models of cantilevered roofs, the dimension in along-wind direction is larger than in cross-wind direction. The flow field characterized by impinging, separation at the windward, and reattachment at the wake zone produces the difficulties with precision of numerical wind tunnel.

\section{Effects of Important Geometrical Parameters and Terrain Type on Wind Pressure Distribution of Spatial Structures with Typical Shapes}

It is difficult to research the influence of different geometrical parameters on the wind pressure distribution of spatial structures by the wind tunnel test. However, such research can be conducted by the CFD. According to the project experience and some existing wind tunnel tests, for the spherical shell model and saddle-shaped shell model, it is taken as $H / D=0,1 / 8$, and $1 / 4$, and $f / D=1 / 3,1 / 4$, and $1 / 5$ to consider the effect of geometrical parameters; for the cylindrical shell model, it is taken as $H / D=0,1 / 8$, and $1 / 4$, $f / D=1 / 3,1 / 4$, and $1 / 5$, and $L / D=1,2,3,4$, and 5 to consider the effect of geometrical parameters; for the cantilevered roofs, it is taken as $b / a=1,2,3,4,5.2$, and $7, \beta=-10^{\circ},-5^{\circ}, 0^{\circ}$, $5^{\circ}$, and $10^{\circ}$, and $f / D=1 / 3,1 / 4$, and $1 / 5$ to consider the effect of geometrical parameters. Adopting the RNG model simulates the wind pressure field of the spherical roofs and the cylindrical roofs, and adopting the Realizable model simulates the wind pressure field of the saddle-shaped roofs and the cantilevered roofs. The wind pressure field of the roofs with different aerodynamic geometrical parameters is simulated under terrain II.

4.1. For Roofs with Spherical Surfaces. In the numerical wind tunnel, the mean pressure coefficient distributions with different $H / D$ and $f / D$ are shown in Figures 11 and 12, respectively. It can be seen that the net value of pressure on the roof could insignificantly change with $H / D$ increasing, while the positive pressure of the leading edge and the peak value of the wind suction increase gradually with $f / D$ increasing, which means that the net value of pressure on the roof would increase as $f / D$ increases. 


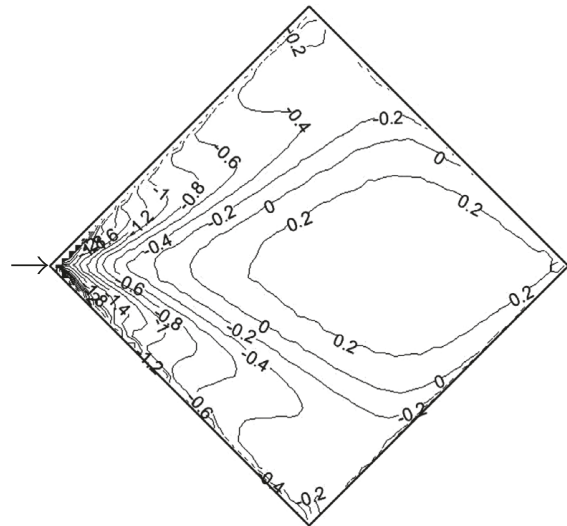

(a)

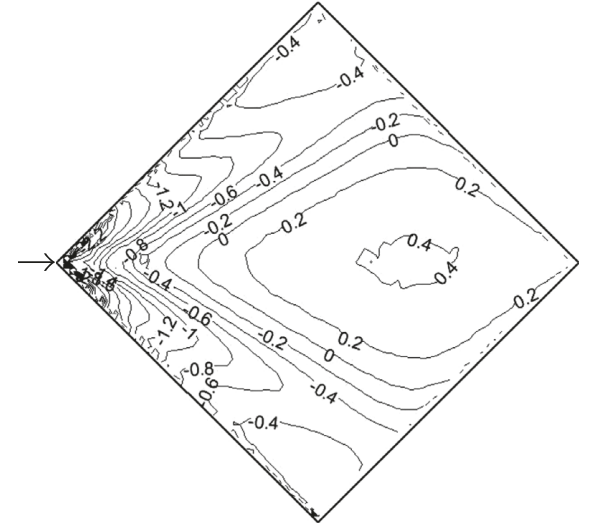

(b)

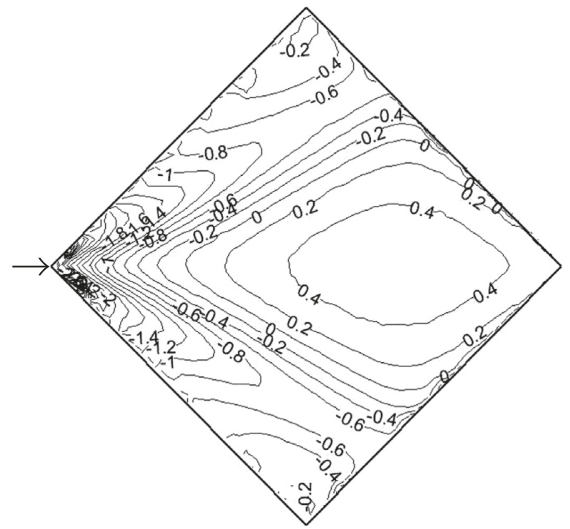

(c)

Figure 19: Mean pressure coefficient distributions of the saddle-shaped model $(H / D=0)$. (a) $f / D=1 / 5$, (b) $f / D=1 / 4$, and $(\mathrm{c}) f / D=1 / 3$.

The results of adopting the RNG model to predict the mean wind pressure coefficients under different terrain types are given in Figure 13. The power law exponent $\alpha$ under terrains I, II, III, IV, and V based on AIJ is $0.10,0.15,0.20$, 0.27 , and 0.35 , respectively. As shown in Figure 13, when $\phi<30^{\circ}$ and $\phi>150^{\circ}$, the wind pressure for roofs is positive, while $30^{\circ}<\phi<150^{\circ}$, the wind pressure for roofs is negative. When $\phi=90^{\circ}$, the differences of the mean pressure coefficients under different terrain types are biggest. When $\phi>150^{\circ}$, the differences of the mean wind pressure coefficients under different terrain types are small. The experiment result showed that when $\alpha>0.23$, the effect of terrain type on the pressure field of the spherical roof is insignificant, while the numerical wind tunnel showed that it needs $\alpha>0.27$.

4.2. For Roofs with Cylindrical Surfaces. In numerical wind tunnel, the mean pressure coefficient distributions of the cylindrical roofs with different $H / D, L / D$, and $f / D$ are shown in Figures 14-16, respectively. It can be seen that the net value of pressure on the roof changes slightly with $H / D$ changing. The effect of $L / D$ on the wind suction is significant. When $L / D<3$, the wind suction at the top of roof increases gradually with $L / D$ increasing, while when $L / D>3$, the wind suction at the top of roof changes insignificantly. The positive pressure at the windward side changes insignificantly, the suction at the central zone and the positive pressure at the wake increases gradually as $f / D$ increases. When $f / D=1 / 4$ and $1 / 5$, the numerical wind tunnel shows the flow reattachment downstream.

The results of adopting the RNG $k-\varepsilon$ model to simulate the mean pressure coefficients under different terrain types are shown in Figure 17. It can be seen that, at the central zone, the differences of the mean pressure coefficients under different terrain types are biggest. The positive pressure at the windward side and the suction at the central zone decrease with $\alpha$ increasing. It can also be seen that the differences of terrains III, IV, and V are small, which means when $\alpha>0.2$, the effect of terrain type on the mean pressure coefficients is insignificant.

4.3. For Roofs with Saddle-Shaped Surfaces. The wind pressure distributions of the saddle-shaped roofs in numerical wind tunnel, taken as $f / D=1 / 3,1 / 4$, and $1 / 5$ and $H / D=0,1 / 8$, and $1 / 4$, are shown in Figures 18 and 19. It can be seen that the effect of $H / D$ on the wind pressure filed as a whole is significant. The wind pressure distribution changes little with $H / D=1 / 8$ and $1 / 4$. The positive pressure at the wake and the negative pressure at the two low points of zone are slightly larger than the other situation. It can also be seen that whole influence on the pressure field 


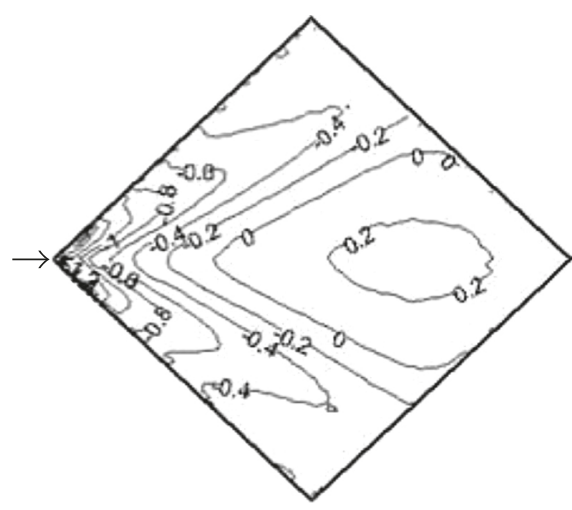

(a)

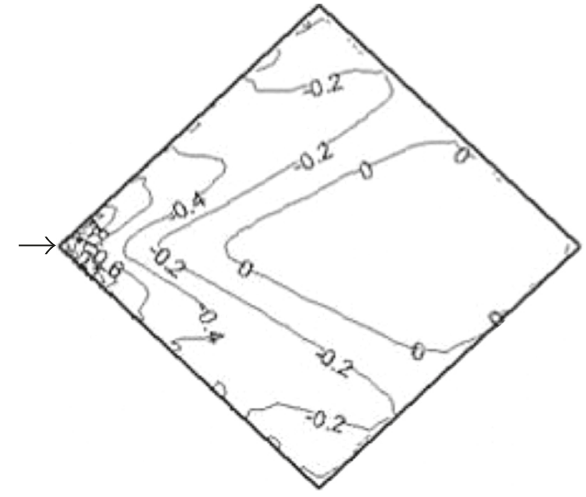

(b)

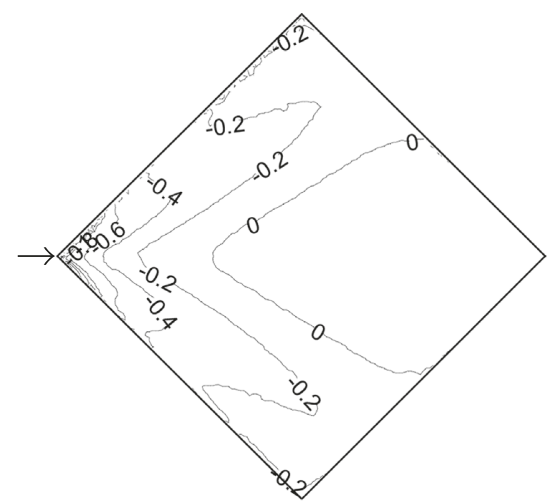

(c)

FIGURE 20: Mean pressure coefficient distributions predicted with the Realizable models under different terrain types (C and D according to GB50009-2012 and V according to AIJ). (a) Terrain C ( $\alpha=0.22)$, (b) terrain D $(\alpha=0.30)$, and (c) terrain V $(\alpha=0.35)$.

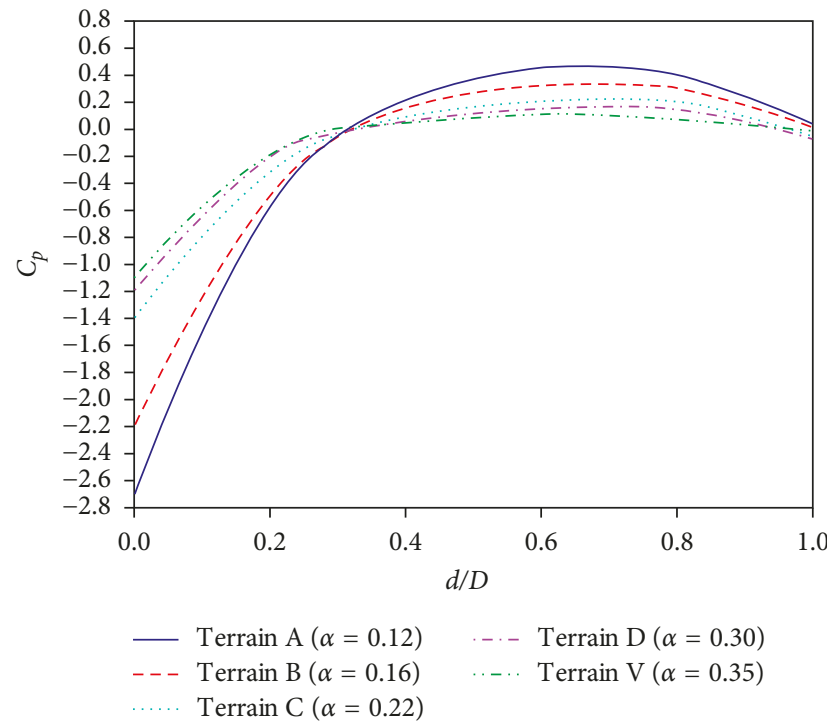

(a)

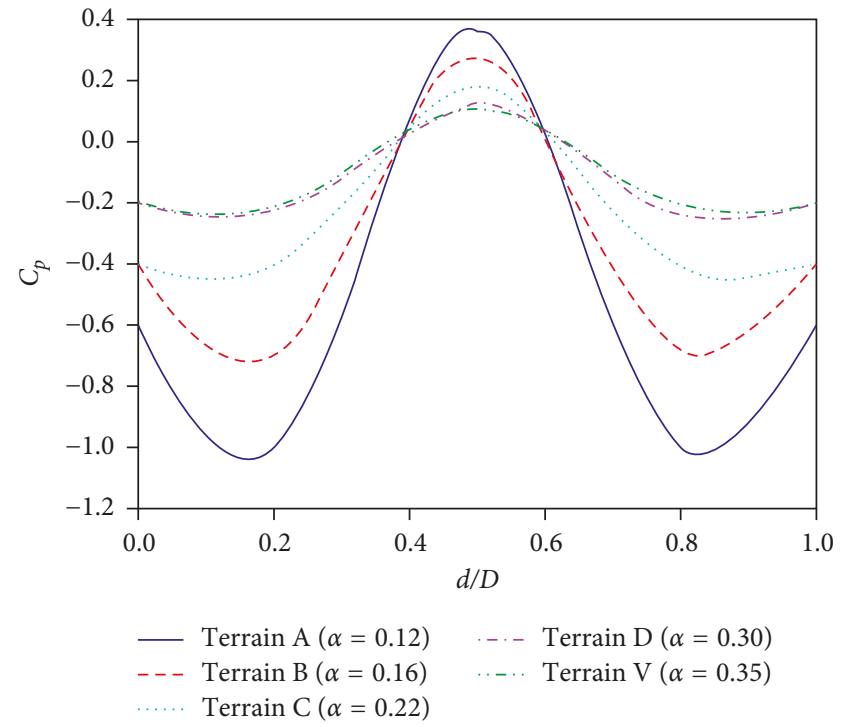

(b)

FIGURE 21: Mean pressure coefficient distributions under different terrain types (C and D according to GB50009-2012 and V according to AIJ). (a) Two higher points of line and (b) two lower points of line.

increases with $f / D$ increasing. The suction in the front of the windward side increases with $f / D$ increasing. However, the suction peak value changes slightly with $f / D$ changing from
$1 / 10$ to $1 / 12$. The positive value at the wake and the negative value at the two low points of zone increase slightly with $f / D$ increasing. 
TABLE 2: Net value distributions of the cantilevered roofs $\left(b / a=1,2,3,4,5.2\right.$, and $\left.7 ; h / H=0.75 ; \beta=0^{\circ}\right)$.

$b / a=1$

TABle 3: Mean pressure coefficient distributions of the cantilevered roofs $\left(\beta=-10^{\circ},-5^{\circ}, 5^{\circ}\right.$, and $\left.10^{\circ} ; h / H=0.75 ; b / a=5.2\right)$.

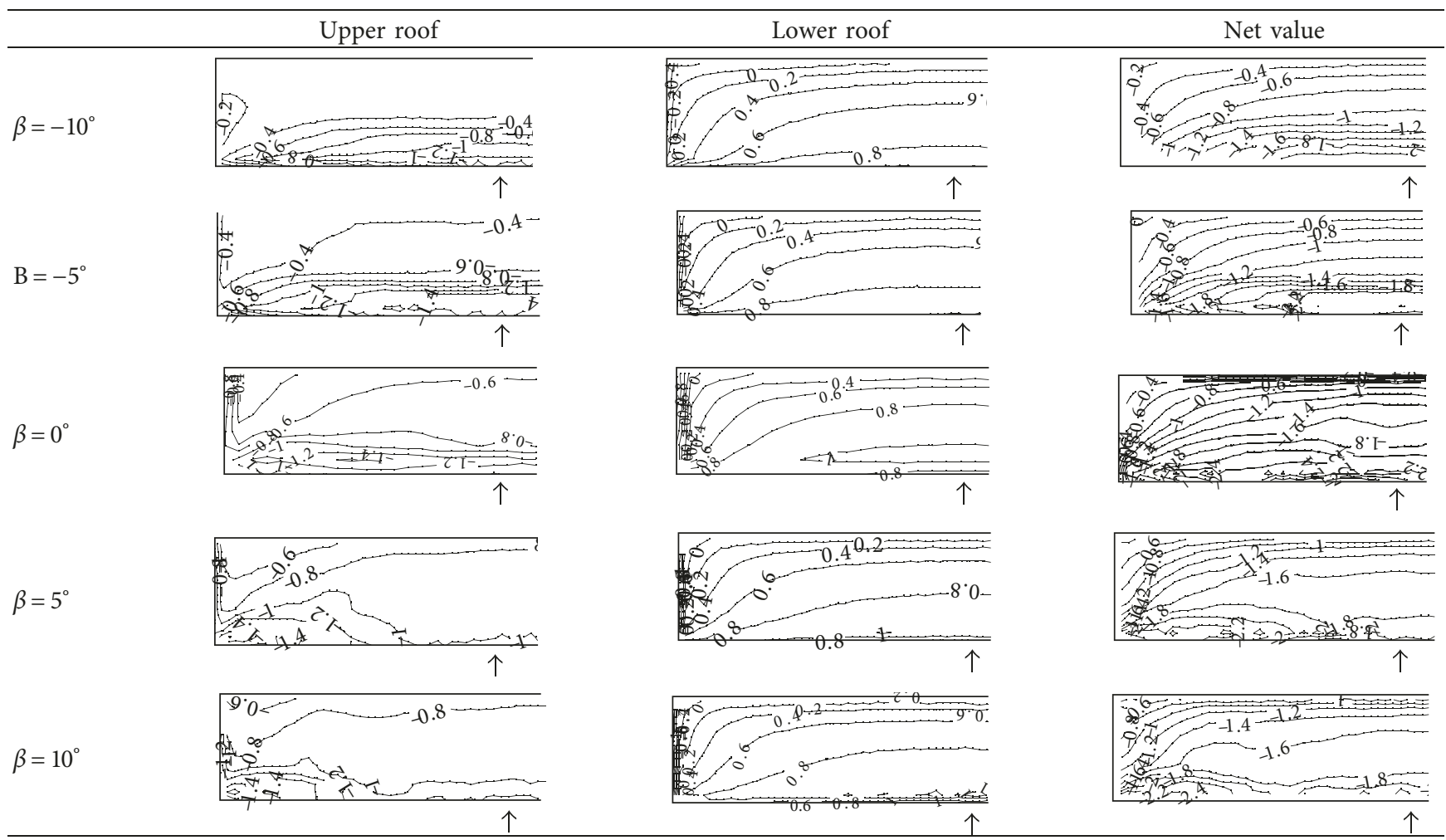

The power law exponent $\alpha$ under the terrains $\mathrm{A}, \mathrm{B}, \mathrm{C}, \mathrm{D}$, and V based on GB50009-2012 is 0.12, 0.16, 0.22, and 0.30, respectively. The results of adopting the Realizable model to simulate the wind field of saddle roof under terrains C and D according to GB50009-2012 and terrain V according to AIJ are shown in Figure 20. The mean pressure coefficient distributions under different terrain types are shown in
Figure 21. In Figures 20 and 21, the turbulence intensity value is selected based on the AIJ. It can be seen that the wind pressure distribution of the saddle-shaped roof is consistent, and the peak value of positive pressure in the front of the roof decreases as $\alpha$ increases. When $\alpha>0.2$, the effect of terrain type on the mean wind pressure distribution of the saddle-shaped roof is insignificant. 
TABLE 4: Mean pressure coefficient distributions of the cantilevered roofs $\left(h / H=0\right.$ and $\left.0.5 ; b / a=5.2 ; \beta=0^{\circ}\right)$.

Upper roof Lower roof

TABLE 5: Mean pressure distributions predicted with the Realizable models under different terrain types (C and D according to GB50009-2012 and V according to AIJ).

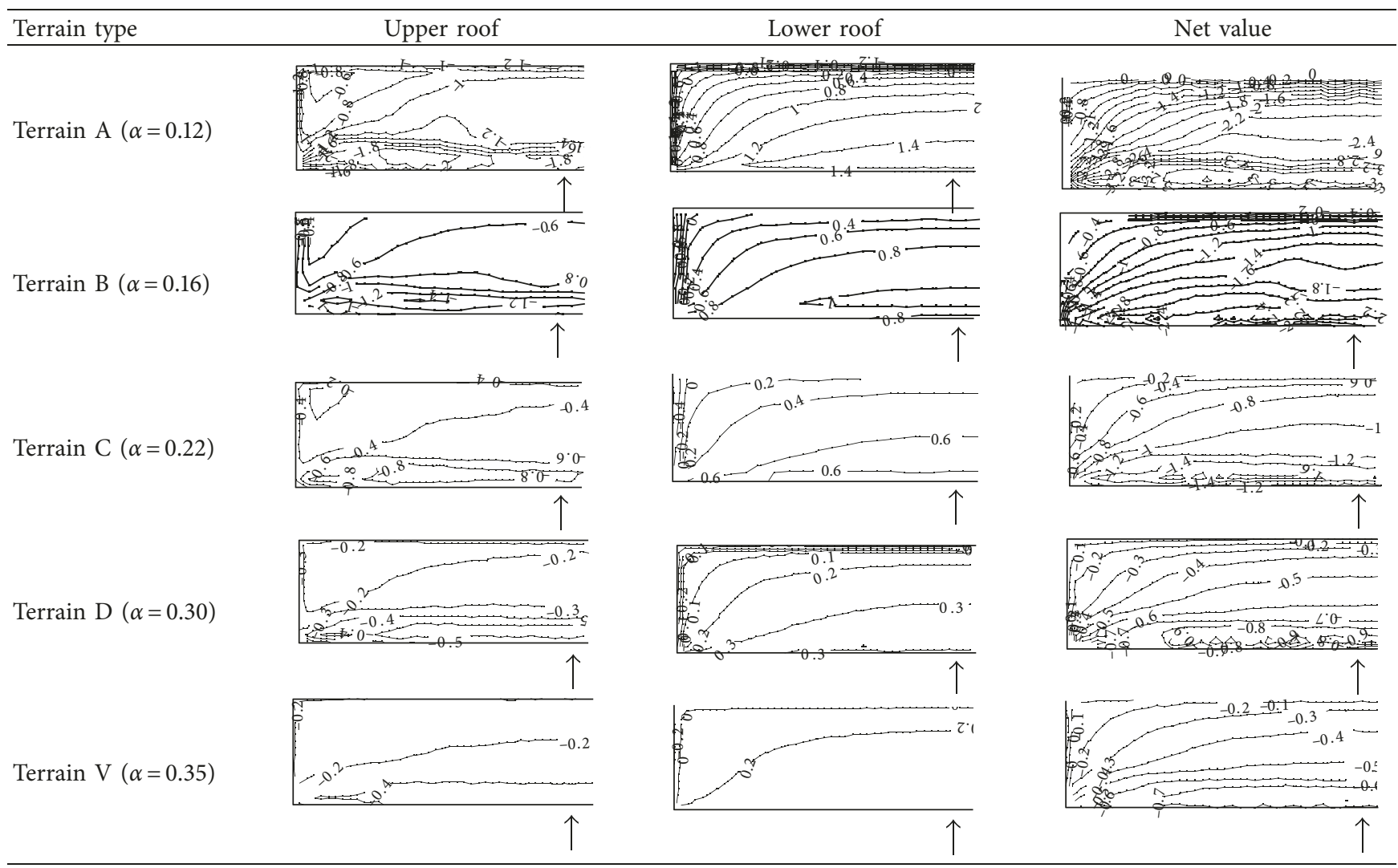

4.4. For Cantilevered Roofs. The wind pressure distributions of the cantilevered roofs in numerical wind tunnel, taken as $b / a=1,2,3,4,5.2$, and $7, \beta=-10^{\circ},-5^{\circ}, 0^{\circ}, 5^{\circ}$, and $10^{\circ}$, and $h / H=0$ and 0.5 , are shown in Tables $2-4$. The roof is taken half in Table 2 when $b / a=4$ and 5.2 in Tables 3 and 4 . It can be seen that the effects of $b / a$ and $\beta$ on the net value distribution of the cantilevered roof are significant, while the effect of $h / H$ is insignificant. When $b / a<3$, the absolute value of high suction at the leading edge increases as $b / a$ increases. When $b / a=5.2$ and 7 , the difference of the suction for the whole roof is slight. According to the mean pressure coefficient distributions in Table 3, for the upper surface, when $\beta=5^{\circ}$ and $10^{\circ}$, two localized regions of high negative pressure are found towards the two ends of the roof span, while $\beta=0^{\circ},-5^{\circ}$, and $-10^{\circ}$, the uniformly high suction region is found along the entire span of the windward edge. This phenomenon can also be found in the wind tunnel test [21]. For lower surface, the mean wind pressure distributions of all roof inclinations are very similar to those of the horizontal roof. As shown in Table 4, when the blockage is offered by the downstream, the net value of whole mean pressure changes slightly as $h / H$ increases. The suction at the leading edge increases as $h / H$ increases.

The wind pressure distributions of the cantilevered roofs derived by the Realizable $k-\varepsilon$ model under the terrains $\mathrm{A}, \mathrm{B}$, 


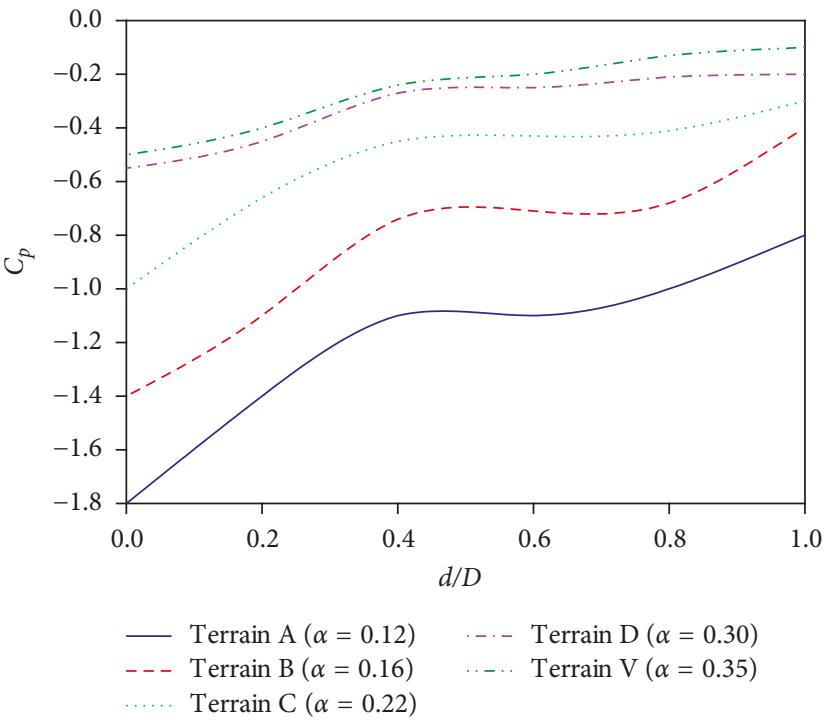

(a)

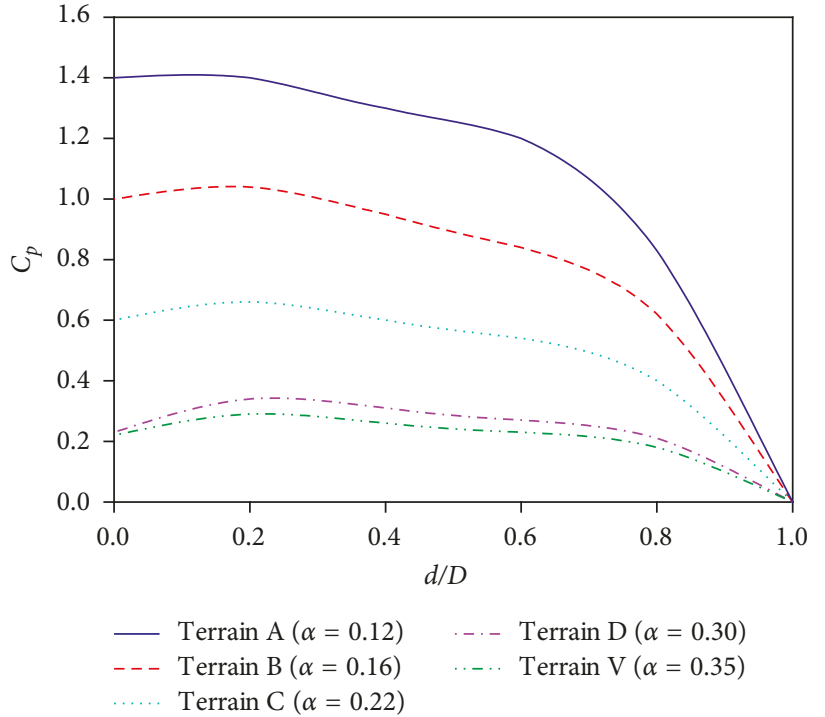

(b)

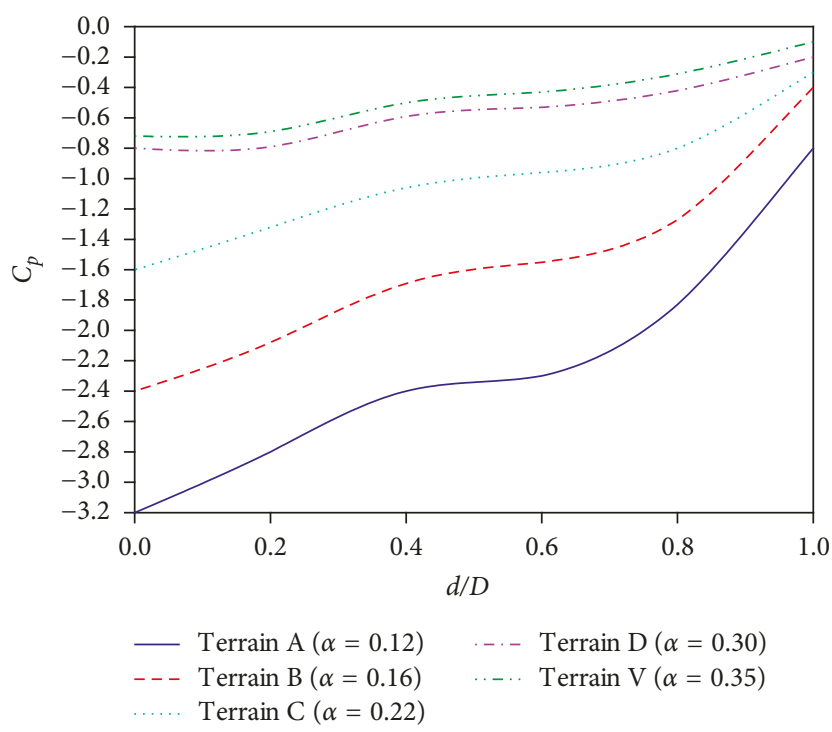

(c)

Figure 22: Mean pressure distributions predicted with the Realizable models under different terrain types (C and D according to GB50009-2012 and V according to AIJ). (a) Upper roof, (b) lower roof, and (c) net value.

C, and D according to GB50009-2012 and under the terrain $\mathrm{V}$ adoption of AIJ are given in Table 5. The turbulence intensity is used as the definition of AIJ. As shown in Table 5, pressure contour in the middle of the upper roof is more sparse than in the other places. It seems to imply that separation bubble occurs in this region and leads to the wind pressure gently changing.

The mean pressure coefficient distributions under different terrain types are shown in Figure 22. It can be seen that the suction on the upper roof, the positive pressure on the lower roof, and the net values of roof decrease as $\alpha$ increases. The difference of the mean wind pressure under terrains $\mathrm{D}$ and $\mathrm{V}$ is slight. When $\alpha>0.27$, the effect of terrain type on the cantilevered roof of the mean wind pressure distribution is insignificant. The result shows that comparing to sphere roofs, cylinder roofs, and saddleshaped roofs, the cantilever roofs are more sensitive to terrain type.

\section{Conclusions}

The characteristics of wind load on large-span roofs are complicated by their unique geometrical configurations and strong dependence on aerodynamic geometrical parameters and terrain type. Hence, this paper is aimed to investigate the effects of geometrical parameters of roofs and terrain type on the wind pressure field. This paper simulated the wind loads of full-scale structures by the use of CFD, and the results were compared with the existing wind tunnel test. It can be concluded that the accuracy of CFD predictions is pretty 
good at the windward side and at the central zone but not perfect as the difference at the wake. For spherical and cylindrical roofs, the mean pressure coefficients given by the RNG model are relatively closer to wind tunnel test results than by the Realizable model, while for saddle-shaped roofs and cantilevered roofs, the difference between two turbulence models is insignificant. With comparative analyses of the wind pressure distribution of the roofs predicted by CFD under different cases, the effects of shape ratios, especially rise-span ratio, height-span ratio, length-span ratio, and so on, and terrain type on the typical spatial structures were presented as follows:

(1) For spherical roofs, cylindrical roofs, and saddleshaped roofs, the effect of $H / D$ on the mean pressure distribution is insignificant, while the effect of $f / D$ is significant.

(2) For spherical roofs, the net value of pressure on the whole roof would increase as $f / D$ increases.

(3) For cylindrical roofs, when the $L / D<3$, the wind suction at the top of the roof increases gradually with $L / D$ increasing. However, the influence of $L / D$ on the mean pressure distribution of the leading edge and the downstream is insignificant. The net values of pressure at the central zone and at the wake increase gradually as $f / D$ increases.

(4) For saddle-shaped roofs, the suction in the front of the windward side increases with $f / D$ increasing, while the influence of $f / D$ on the net value of pressure at the wake and at the two low points of zone is insignificant.

(5) For cantilevered roofs, the effects of $b / a$ and $\beta$ on the net values distribution of the cantilevered roof are significant, while the effect of $h / H$ is insignificant. When $b / a<3$, the absolute value of high suction at the leading edge increases as $b / a$ increases. When $b / a=5.2$ and 7 , the difference of the suction for the whole roof is slight. When $\beta$ changes from $0^{\circ}$ to $10^{\circ}$, the form of the flow separation may change at the leading edge. For the upper surface, when $\beta=5^{\circ}$ and $10^{\circ}$, two localized regions of high negative pressure are found towards the two ends of the roof span. For lower surface, the mean wind pressure distributions of all roof inclinations are very similar to those of the horizontal roof. This phenomenon can also be found in the wind tunnel test.

(6) When the power law exponent $\alpha>0.27$ for spherical roofs and cylindrical roofs and $\alpha>0.30$ for saddleshaped roofs and cantilever roofs, the influence of terrain type on the mean wind pressure distribution is slight. Comparing to spherical roofs, cylinder roofs and the cantilever roofs are more sensitive to terrain type.

\section{Conflicts of Interest}

The authors declare that there are no conflicts of interest regarding the publication of this paper.

\section{Acknowledgments}

The authors are grateful to the financial support of the National Key Research and Development Program of China (2016YFC0802205), the Natural Science Foundation of China (no. 51608453), and the Fundamental Research Funds for the Central Universities (A0920502051619-8).

\section{References}

[1] J. Wang, Spatial Organization and Structure. The International Encyclopedia of Geography, John Wiley \& Sons, Ltd., Hoboken, NJ, USA, 2017.

[2] J. Wang, J. D. Zhao, T. Lan, J. H. Qian, and T. Song, Development Progress and Future Prospect of Large-Span Spatial Structures, Building Science, Seattle, WA, USA, 2013.

[3] J. Franke, Introduction to the Prediction of Wind Loads on Buildings by Computational Wind Engineering (CWE). Wind Effects on Buildings and Design of Wind-Sensitive Structures, Springer Vienna, Vienna, Austria, 2007.

[4] J. Franke, C. Hirsch, A. G. Jensen et al., "Recommendations on the use of CFD in wind engineering," in Proceedings of the International Conference on Urban Wind Engineering and Building Aerodynamics, Rhode-Saint-Genèse, Belgium,, May 2004.

[5] S. Kawamura, T. Kiuchi, and T. Mochizuki, "Characteristics of wind pressure acting on spatial large dome," Journal of Wind Engineering and Industrial Aerodynamics, vol. 42, no. 1-3, pp. 1511-1512, 1992.

[6] J. Blessmann, "Researches on wind effects on domes in Brazil," Journal of Wind Engineering and Industrial Aerodynamics, vol. 65, no. 1-3, pp. 167-177, 1996.

[7] T. Hongo, M. Suzuki, and M. Tsuchiya, "Experimental study of wind forces on spherical roofs," Journal of Wind Engineering, vol. 68, pp. 1-14, 1996.

[8] J. Blessmann, "Aerodynamic studies for the Brazilian wind code," in Proceedings of the 10th Americas Conference on Wind Engineering, pp. 31-70, Baton Rouge, LA, USA, 2005.

[9] Y. Q. Li, Y. Tamura, and Z. Y. Shen, "Wind tunnel tests for wind pressure distribution on spherical shells," Journal of Building Structures, vol. 26, no. 5, pp. 104-111, 2005.

[10] F. H. Li, Z. H. Ni, and S. Z. Shen, "Characteristics of wind pressure on typical roofs under different terrain conditions," Journal of Building Structures, vol. 28, no. 1, pp. 119-124, 2007.

[11] M. J. Paluch, A. M. Loredo-Souza, and J. Blessmann, "Wind loads on attached canopies and their effect on the pressure distribution over arch-roof industrial buildings," Journal of Wind Engineering and Industrial Aerodynamics, vol. 91, no. 8, pp. 975-994, 2003.

[12] P. A. Blackmore and E. Tsokri, "Wind loads on curved roofs," Journal of Wind Engineering and Industrial Aerodynamics, vol. 94, no. 11, pp. 833-844, 2006.

[13] Y. Q. Li, Y. Tamura, and Z. Y. Shen, "Wind tunnel tests for wind pressure distribution characteristics on cylindrical shells," Journal of Tongji University, vol. 34, no. 11, pp. 1457-1463, 2006.

[14] B. Chen and Q. S. Yang, "Effects of geometrical factors on wind pressure characteristics of cylindrical roofs with wind tunnel tests," Applied Mechanics and Materials, vol. 351-352, pp. 284-289, 2013.

[15] A. J. Dutt, "Wind pressure distribution on a multiple hyperbolic parabolic shell roof building," Space Structures, vol. 1, pp. 225-230, 1986.

[16] C. Zhao, Q. N. Lu, and S. Z. Shen, "Wind pressure distribution on hyperbolic paraboloid shell roofs," Journal of Harbin 
University of Civil Engineering and Architecture, vol. 24, no. 1, pp. 29-36, 1991.

[17] Y. Sun, "Characteristics of wind loading on long-span roofs," Doctoral Dissertation, Harbin Institute of Technology, Harbin, China, 2007.

[18] X. Dong and J. H. Ye, "Area-averaged wind pressure on a saddle roof," Journal of Vibration and Shock, vol. 30, no. 7, pp. 21-30, 2011.

[19] M. Liu, X. Chen, and Q. Yang, "Characteristics of dynamic pressures on a saddle type roof in various boundary layer flows," Journal of Wind Engineering and Industrial Aerodynamics, vol. 150, pp. 1-14, 2016.

[20] F. Li, X. Chen, and M. Gu, "Wind load characteristics and wind induced responses of saddle-shape cable nets roof in different terrains," in Proceedings of the International Colloquium on Bluff Body Aerodynamics and Applications, Boston, MA, USA, June 2016.

[21] J. G. Zhao and K. M. Lam, "Occurrence of peak lift on a large cantilevered roof," in Proceedings of the First International Symposium on Wind \& Structures for Century, pp. 217-226, Cheju, Korea, January 2000.

[22] J. G. Zhao and K. M. Lam, "Characteristics of wind pressures on large cantilevered roofs: effect of roof inclination," Journal of Wind Engineering and Industrial Aerodynamics, vol. 90, no. 12-15, pp. 1867-1880, 2002.

[23] A. Katsumura, Y. Tamura, and O. Nakamura, "Universal wind load distribution simultaneously reproducing largest load effects in all subject members on large-span cantilevered roof," Journal of Wind Engineering and Industrial Aerodynamics, vol. 95, no. 9-11, pp. 1145-1165, 2007.

[24] Y. Tominaga, A. Mochida, R. Yoshie et al., "AIJ guidelines for practical applications of cfd to pedestrian wind environment around buildings," Journal of Wind Engineering and Industrial Aerodynamics, vol. 96, no. 10-11, pp. 1749-1761, 2008.

[25] P. J. Richards, A. D Quinn, and S. Parker, "A 6m cube in an atmosphere boundary layer flow Part 2. Computational solutions," Wind and Structures, vol. 5, no. 2-4, pp. 177-192, 2002.

[26] Architectural Institute of Japan, Recommendations for Loads on Buildings, Architectural Institute of Japan, Tokyo, Japan, in Japanese, 2004.

[27] GB50009-2012, Load Code for the Design of Building Structures, China Architecture \& Building Press, Beijing, China, in Chinese, 2012.

[28] Australian/New Zealand Standard, Structural Design Actions, Part 2: Wind Actions, AS/NZS 1170.2, Standards Australia, Sydney, Australia, 2002. 


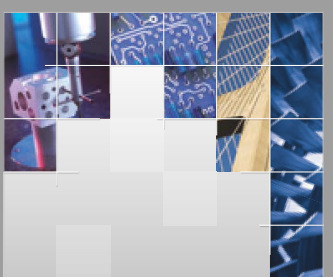

\section{Enfincering}
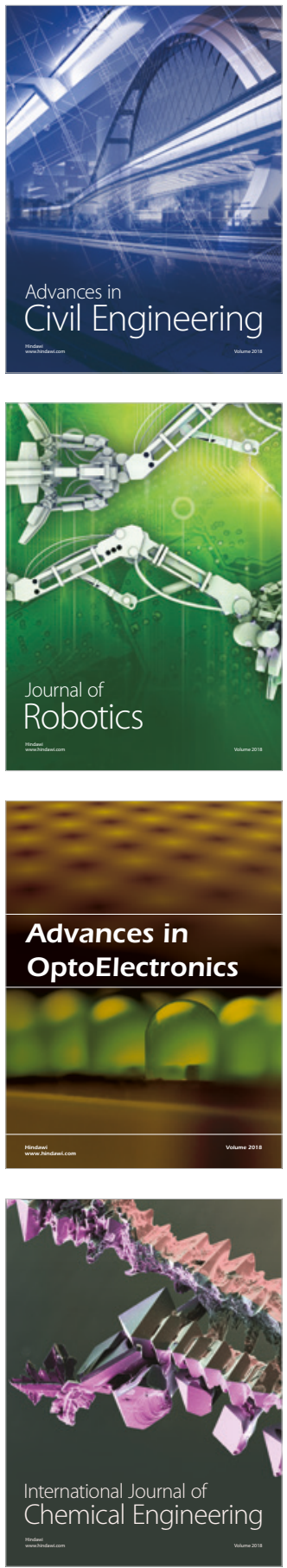

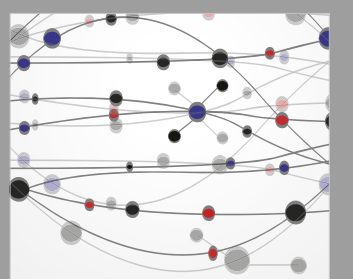

\section{Rotating \\ Machinery}

The Scientific World Journal

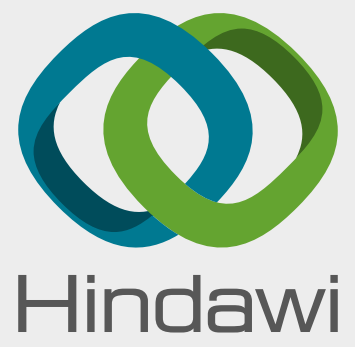

Submit your manuscripts at

www.hindawi.com
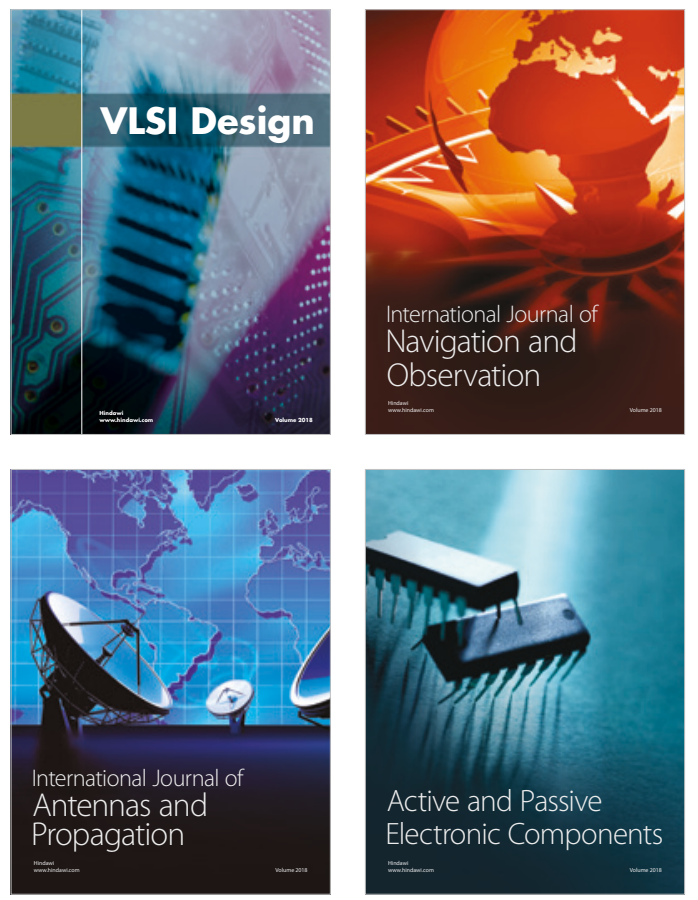
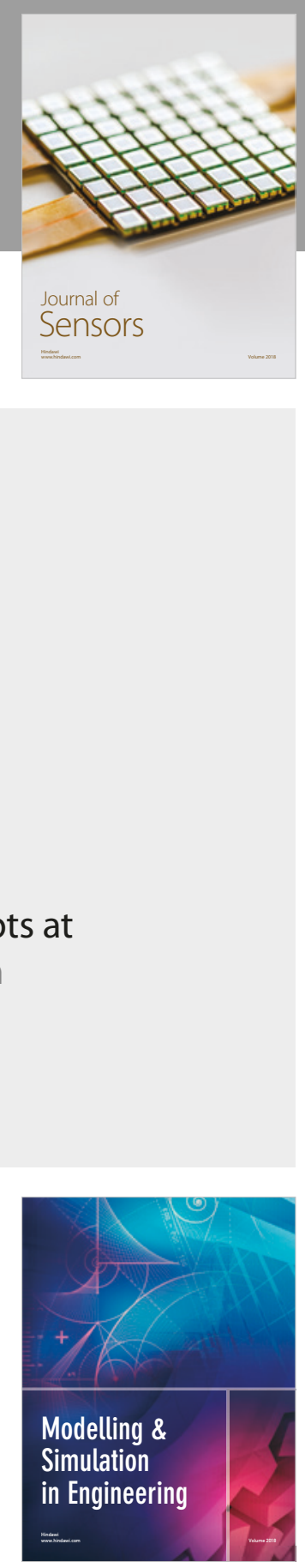

\section{Advances \\ Multimedia}
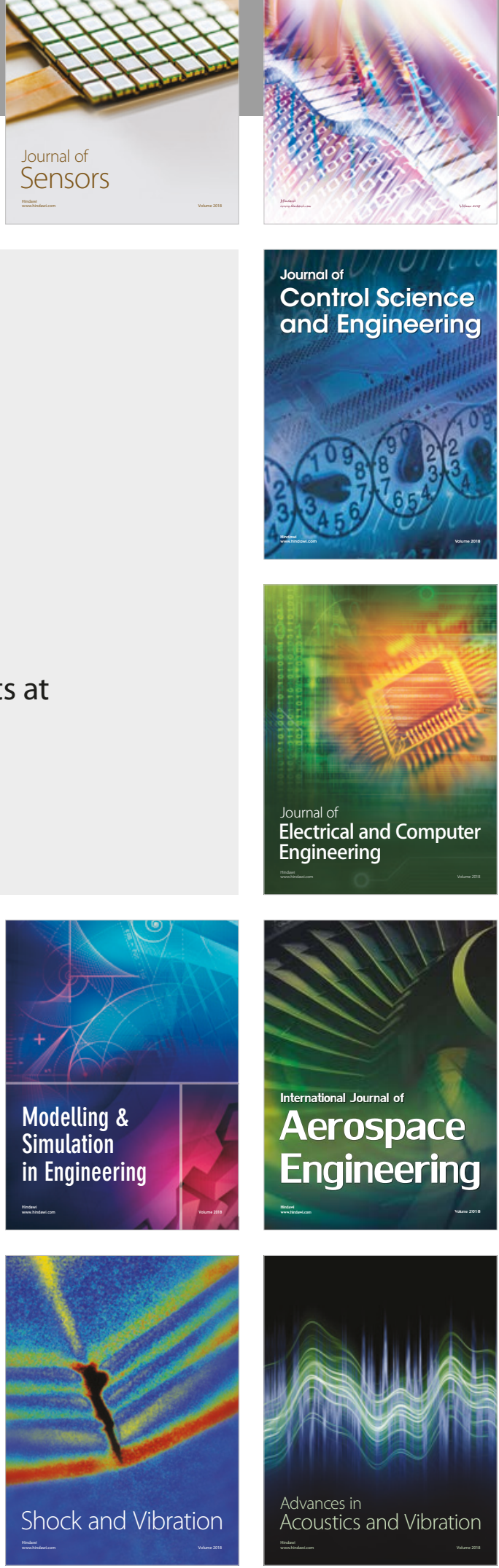